\title{
Numerical Investigation of Development Processes of Baiu Frontal Depressions. Part II: An Idealized Study
}

\author{
Eigo TOCHIMOTO and Tetsuya KAWANO \\ Department of Earth and Planetary Sciences, Kyushu University, Fukuoka, Japan \\ (Manuscript received 26 December 2015, in final form 3 April 2017)
}

\begin{abstract}
In Part I of this study, the development processes of Baiu frontal depressions (BFDs) have been examined through case-study numerical experiments. The numerical simulations revealed that latent heating is dominant for the development of BFDs in the western part of the Baiu frontal zone (W-BFDs), west of approximately $140^{\circ} \mathrm{E}$, while both latent heating and baroclinicity are important for the development of BFDs in the eastern part of the zone (E-BFDs), east of approximately $140^{\circ} \mathrm{E}$. In this study, idealized numerical simulations with zonally homogeneous basic fields are conducted to obtain a more generalized perspective of the development processes of BFDs.

The basic fields for the idealized simulations are made from the composites of the environments under which $28 \mathrm{~W}-\mathrm{BFDs}$ and 43 E-BFDs developed. The idealized simulations successfully reproduce a realistic W-BFD and E-BFD. The W-BFD has a slightly westward-tilted vertical structure, modulated by latent heating at low levels of the atmosphere. In contrast, the E-BFD has a westward-tilted structure through the troposphere, similar to the well-known baroclinic wave structure. Results of available potential energy diagnosis for the effects of latent heating and baroclinicity on the BFD development are consistent with those in Part I. The W-BFD has a mechanism mainly driven by latent heating yielding strong convection, while the E-BFD develops through baroclinic instability in moist atmosphere.
\end{abstract}

Keywords Baiu; extratropical depression; depression

\section{Introduction}

Baiu frontal depressions (hereafter, BFDs), which form and develop in the Baiu frontal zone, are major disturbances of the summer monsoon season in East Asia. The Baiu frontal zone has a multi-scale structure in which meso- $\alpha$-, meso- $\beta$-, and meso- $\gamma$-scale cloud systems are embedded within a synoptic scale circulation system (Ninomiya and Akiyama 1992). Thus, such systems may play an important role in the dynamics of BFDs.

Corresponding author and present affiliation: Eigo Tochimoto, Atmosphere and Ocean Research Institute, The University of Tokyo, 5-1-5 Kashiwanoha, Kashiwa, Chiba 277-8564, Japan

E-mail: Tochimoto@aori.u-tokyo.ac.jp

J-stage Advance Published Date: 12 April 2017

(C)2017, Meteorological Society of Japan
A large number of BFDs have baroclinic wavelike features (Akiyama 1984, 1990a, b; Chang et al. 1998); these BFDs develop in a baroclinic field and have a structure tilted westward with height (Akiyama 1990a, b; Tochimoto and Kawano 2012, hereafter TK12). However, low-level baroclinicity in the Baiu frontal zone is notably weaker than that in ordinary frontal zones. Thus, the effects of baroclinicity on the BFD development may differ from those observed for extratropical depression development.

Many previous studies have suggested that latent heating associated with condensation of water vapor is important to the BFD development (Akiyama 1984, 1990a, b; Ninomiya and Kurihara 1987; Chang et al. 1998; Ninomiya and Shibagaki 2003; Shibagaki and Ninomiya 2005; Tagami et al. 2007). Chang et al. (1998) found that latent heating largely contributes to the BFD intensification in the early development 
stage. Tagami et al. (2007) performed a numerical simulation for a BFD on 20 June 2001 and demonstrated that the BFD was not reproduced in their simulation in which latent heating was excluded. However, these previous studies are limited to case studies.

The effects of differences in environmental characteristics between the western and eastern parts of the Baiu frontal zone on the BFD development were examined by TK12. The western part of the Baiu frontal zone (west of approximately $140^{\circ} \mathrm{E}$ ) is characterized by weak baroclinicity and a strong water vapor gradient, while the eastern part (east of approximately $140^{\circ} \mathrm{E}$ ) is characterized by relatively strong baroclinicity and a weak water vapor gradient (Matsumoto et al. 1971; Ninomiya and Akiyama 1992). In TK12, the BFDs that developed in the western and eastern parts of the Baiu frontal zone were classified into W-BFDs and E-BFDs, respectively. They investigated differences in effects of baroclinicity and latent heating between W-BFDs and E-BFDs using reanalysis data for eight years (2000-2007) and revealed that latent heating intensifies both types of BFDs. The effect of latent heating was larger in the W-BFD development. Their work also suggested that both low-level baroclinicity and latent heating are important to the E-BFD development.

Tochimoto and Kawano (2017, hereafter Part I) performed numerical case studies to examine more quantitative contributions of latent heating and baroclinicity to W-BFDs and E-BFDs using the Weather Research and Forecasting (WRF) model (Skamarock et al. 2008). An available potential energy (APE) diagnosis showed the time sequences of those effects: latent heating plays an essential role in the W-BFD development throughout the developing stage, while both latent heating and baroclinicity have large contributions during the E-BFD development. Furthermore, Part I suggested that the W-BFDs have a development mechanism that is mainly driven by latent heating. In the early development stage, low-level potential vorticity (PV) is intensified near the W-BFD center. Thus, the low-level vorticity is enhanced near the cyclone center. In the later stage, in addition to the advection of warm and moist air to the front of the center, associated with the vortex circulation, the low-level temperature gradient is intensified in this region, which leads to the initiation of active convection. As a consequence, low-level PV is intensified in front of the W-BFD center.

Idealized numerical experiments are useful to obtain a more generalized perspective of the development processes of BFDs. Previously, there have been a large number of idealized numerical studies for depressions in the extratropics (Montgomery and Farrell 1991, 1992; Takayabu 1991; Whitaker and Davis 1994; Moore and Montgomery 2005; Yanase and Niino 2005, 2007; Moore et al. 2013; Yanase et al. 2015). Such idealized numerical studies should be valuable for understanding the dynamics of BFDs developing in typical Baiu frontal environments. Using idealized numerical experiments can exclude the influences of topography and other disturbances on the BFD development, enabling us to understand the development process more easily.

Thus, we perform idealized numerical simulations in zonally homogeneous environments for W-BFDs and E-BFDs to generalize the effects of latent heating and baroclinicity on the BFD development and to obtain further insight into the development mechanism of BFDs. This study is organized as follows. Section 2 gives the model and experimental designs. In Section 3 , we show the evolutions, structures, and development processes of each type of BFD. In Section 4, we discuss the development mechanisms of W-BFDs and E-BFDs. The conclusions are presented in Section 5.

\section{Model and methodology}

\subsection{Model}

The WRF version 3.3 model is used in this study. The model domain is set to be $4000 \mathrm{~km} \times 4000 \mathrm{~km}$ in the horizontal directions and the horizontal grid spacing is $20 \mathrm{~km}$. The domain had 72 vertical levels and the model top is $18 \mathrm{~km}$. The center of the domain is $x=0 \mathrm{~km}, y=0 \mathrm{~km}$. The WRF single moment 6-class (WSM6) explicit moisture scheme (Hong and Lim 2006), Grell-3d cumulus scheme (Grell and Dévényi 2002), Noah land-surface model (Chen and Dudhia 2001), and Yonsei University (YSU) planetary boundary scheme (Noh et al. 2003) are applied in the experiments. The simulations with the Grell cumulus scheme reproduced a well-developed W-BFD, while those with the Kain Frithch scheme (Kain 2004), which was also used in Part I, simulated fairly weak convection and a W-BFD. Thus, the Grell scheme is adopted in the idealized simulations. Periodic and open conditions are adopted at the zonal and meridional boundaries, respectively. The lower boundary is set as the sea, with fixed sea surface temperatures (SSTs) equal to the initial surface air temperatures at each grid. The upper boundary has a sponge layer above $14 \mathrm{~km}$. The experiments adopting the above settings are denoted as control simulations (CNTLs). To investigate the impacts of latent heating on the BFD development, additional experiments, termed NOLH, 
in which latent heating is excluded, were carried out. In the NOLH, surface heat, moisture, and momentum fluxes remain, but there is neither condensation heating nor cooling. The CNTLs (NOLHs) for the W-BFD and E-BFD are denoted as W-CNTL (W-NOLH) and E-CNTL (E-NOLH), respectively.

\subsection{Basic fields}

In this study, the definitions of W-BFDs and E-BFDs are same as in TK 12. They first defined developed BFDs as the central sea level pressure (SLP) falling $4 \mathrm{hPa}$ or more from the time of formation. Then, developed BFDs were categorized into two groups: BFDs that developed in the region west of $140^{\circ} \mathrm{E}$ (W-BFD; 28 cases) and those that developed in the region east of $140^{\circ} \mathrm{E}$ (E-BFD; 43 cases).

The basic fields are made from 6-hourly Japanese 25-year Re-Analysis (JRA-25) / Japan Meteorological Agency (JMA) Climate Data Assimilation System (JCDAS) data (Onogi et al. 2007) with a horizontal resolution of $1.25^{\circ} \times 1.25^{\circ}$. For each BFD type, the construction of the basic fields is followed by the procedure below:

1. We take the 5-day mean fields for geopotential and temperature, which are centered on the time $12 \mathrm{~h}$ before each BFD (28 W-BFDs and 43 E-BFDs) reaches the minimum SLP (denoted as KT-12 in TK12).

2. The meridional-height profiles through each BFD center $(x=0 \mathrm{~km}, y=0 \mathrm{~km})$ between $y=-2000 \mathrm{~km}$ and $y=2000 \mathrm{~km}$ are constructed from the mean fields.

3. The constructed profiles are superposed with respect to the cyclone centers for each type of BFDs. Zonal winds are given by the geostrophic balance, in which the Coriolis parameter is set as constant value of $1 \times 10^{-4} \mathrm{~s}^{-1}$, and meridional winds are set as zero. The composite fields are uniformly given in the zonal direction from $x=-2000 \mathrm{~km}$ to $2000 \mathrm{~km}$ for each type of BFDs.

4. Note that the basic fields of water vapor are obtained with the above procedure 2 and 3 except for using instantaneous water vapor fields at KT- 12 . Since water vapor fields in the 5-day mean fields are notably smoothed, active convection for the W-BFD cannot be initiated. We believe that the 5-day mean cannot express the large amount of water vapor observed at the occurrence of BFDs. Thus, we adopt the instantaneous fields in procedure 1 to make the basic field of water vapor. It is strongly suggested that the large amount of low-level water vapor is crucial to the development of W-BFDs.
The meridional-vertical-cross sections of the obtained basic fields are shown in Figs. 1a and 1b. A comparison of the basic fields between the W-CNTL and E-CNTL shows that baroclinicity and amounts of water vapor for the W-CNTL are respectively weaker and larger than those for the E-CNTL.

To examine the features of the environment in which W-BFDs (E-BFDs) develop, the basic field for the W-CNTL (E-CNTL) is compared with the meridional-vertical profile averaged from June to July between 2000 and 2007 along $125^{\circ} \mathrm{E}\left(145^{\circ} \mathrm{E}\right)$. It is suggested that W-BFDs develop in environments where moisture and baroclinicity are stronger compared to the averaged environment. Meanwhile, E-BFDs develop in environments where baroclinicity and moisture are similar to the average environment (not shown).

When the zonally homogeneous basic fields are used as initial conditions, the winds undergo a small anticyclonic oscillation with time. To eliminate this, according to Plougonven and Snyder (2007), all fields including water vapor are integrated without latent heating for $36 \mathrm{~h}$, which roughly corresponds to twice the period of inertial oscillation $(\sim 2 \pi / f)$ and are averaged over $36 \mathrm{~h}$. The obtained fields are defined as new initial conditions. This process is repeated twice. After that, the finally obtained fields are used as the basic fields. The difference between the first conditions and final adjusted fields is on the order of $10^{-2}$ for horizontal wind.

\subsection{Initial disturbance}

A zonally wave-like thermal bubble $T^{\prime}$ is set as follows:

$$
T^{\prime}=T_{0} \cos ^{2}\left(\frac{\pi}{2} \frac{r}{r_{c}}\right) \cos \left(\frac{2 \pi x}{L_{x}}+\pi\right),
$$

where $T_{0}=4 \mathrm{~K}, r=\sqrt{\left(y / r_{y}\right)^{2}+\left(z-z_{c}\right)^{2} / r_{z}^{2}}, r_{y}=$ $400 \mathrm{~km}, z_{c}=8 \mathrm{~km}, r_{z}=8 \mathrm{~km}$, and $L_{x}=2000 \mathrm{~km}$. The distributions of the initial perturbation are shown in Figs. 1c and 1d. The initial bubble activates a baroclinic disturbance growing in the basic fields, although the amplitude of the bubble is somewhat unrealistic. Similar initial disturbances are also used in previous studies (Schultz and Zhang 2007; Tochimoto and Niino 2017). BFDs having deep vertical structure are assumed in this study as we focus on strongly developed BFDs. To develop disturbances with deep vertical structure through the troposphere, the peak of the initial perturbation is located between upper and low levels. We confirmed that the amplitude, peak 
(a) PT \& Moisture for the W-BFD

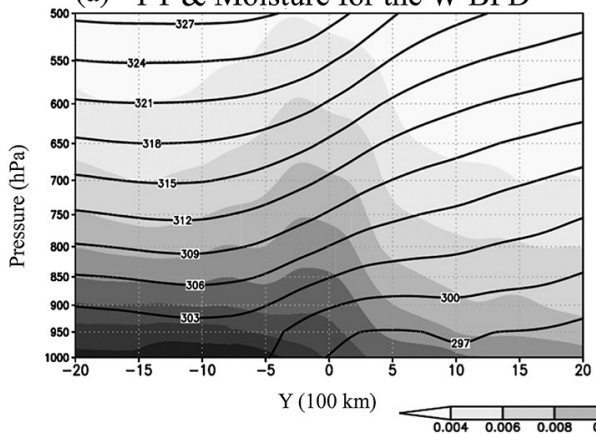

(c)

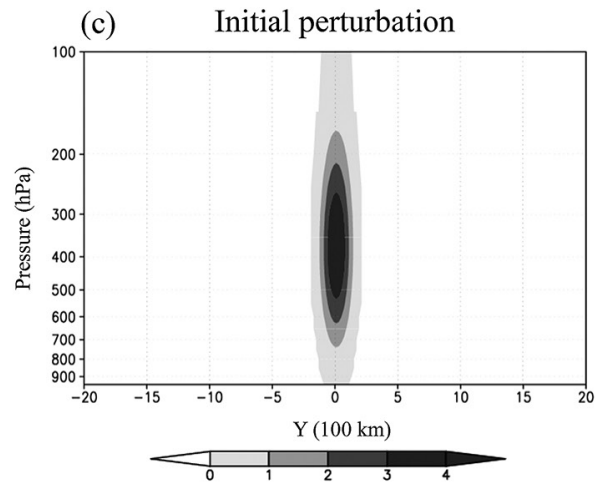

(b) PT \& Moisture for the E-BFD

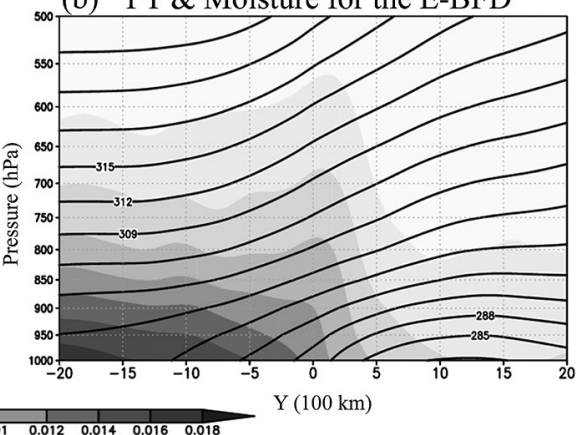

(d) Initial perturbation

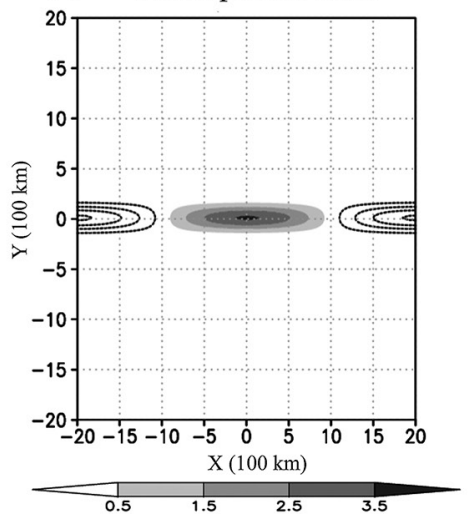

Fig. 1. (a, b) Meridional-height cross sections of environmental fields of specific humidity ( $\mathrm{shading} ; \mathrm{kg} \mathrm{kg}^{-1}$ ) and potential temperature (contour lines; K) for the (a) W-BFD and (b) E-BFD. (c) Meridional-height and (d) horizontal distribution of the initial thermal perturbation (shading; K) at $300 \mathrm{hPa}$. Negative values in (d) are shown by dashed contours.

height, and size of the initial disturbances did not qualitatively alter the development processes of both BFD categories (not shown).

\section{W-BFD}

\subsection{Evolution}

We first describe the evolutions of SLP and vertically integrated condensed water for the W-CNTL (Fig. 2). From $t=0$ to $120 \mathrm{~h}$, a weak and large-scale baroclinic disturbance slowly develops. During that period, no active convection occurs over the domain. It is suggested that the baroclinic disturbance contributes to initiate and maintain active convection that occurs after $120 \mathrm{~h}$. Around $t=120 \mathrm{~h}$, a depression and its associated convection begin to develop (not shown). Ten hours later, active convection is generated near $x=-400 \mathrm{~km} \sim 0 \mathrm{~km}, y=200 \mathrm{~km}$ close to the depression center (Fig. 2a). At $t=140 \mathrm{~h}$, although the convection around the depression center is sustained, another convection also occurs in front (east) of the depression center (Fig. 2b). As a consequence, a large active convection region appears in front of the depression by $t=160 \mathrm{~h}$ (Figs. 2c, d).

The W-BFD has a meridionally elongated structure, which represents the structure of a growing baroclinic disturbance in the basic fields and somewhat differs from that in Part I. This difference could be associated with the features of basic fields. The structures of winds and temperature for the basic fields have more meridionally smoothed features than those for individual cases as the basic fields in the present experiments are obtained from the composite fields. Moreover, zonally homogeneous basic fields also could make the difference from Part I.

The characteristics of precipitation associated with the W-BFD are shown in Fig. 3. The precipitation concentrates within a meridionally narrow region around $y=100-300 \mathrm{~km}$ (Fig. 3a). In that region, the total precipitation accumulated from $t=0-160 \mathrm{~h}$ exceeds, at most, $100 \mathrm{~mm}$. The maximum of hourly 
(a) $T=130$

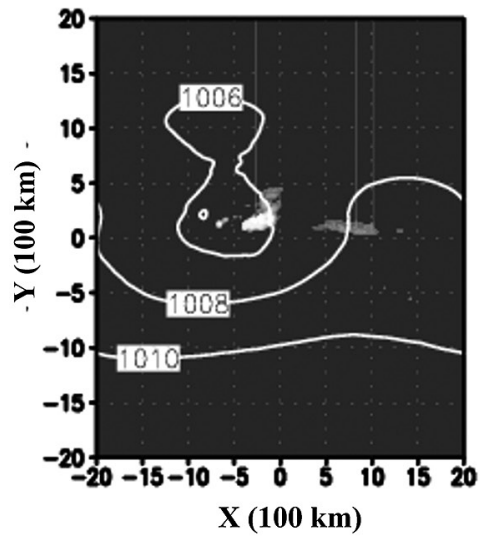

(c) $T=150$

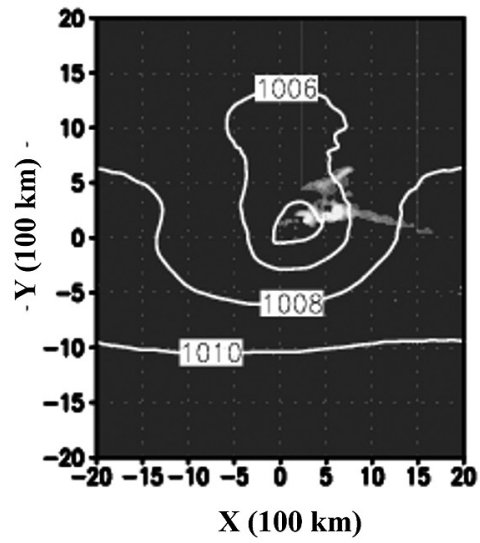

W-CNTL

(b) $T=140$

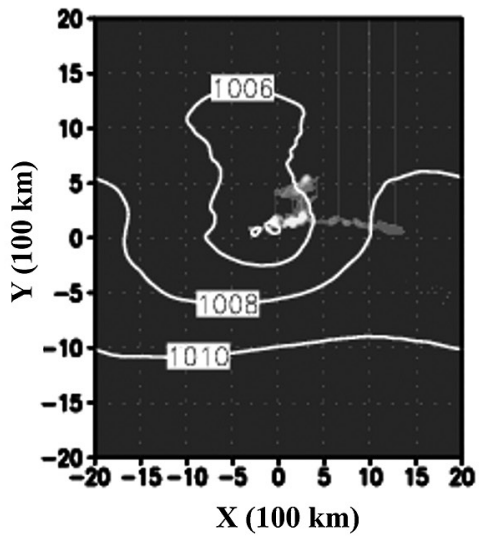

(d) $\mathrm{T}=160$

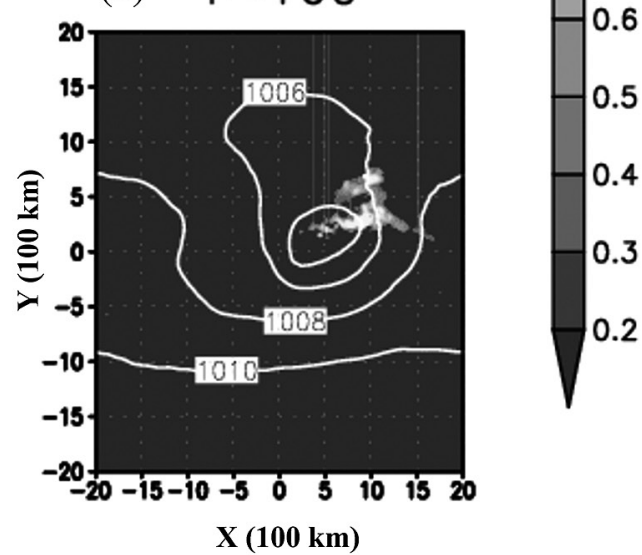

Fig. 2. Vertically integrated condensed water (color shading; $\mathrm{kg} \mathrm{m} \mathrm{m}^{-2}$ ) and SLP (contour lines; $\mathrm{hPa}$ ) for the $\mathrm{W}-\mathrm{CNTL}$ at (a) $t=130 \mathrm{~h}$, (b) $t=140 \mathrm{~h}$, (c) $t=150 \mathrm{~h}$, and (d) $t=160 \mathrm{~h}$. Contour increment is $2 \mathrm{hPa}$.

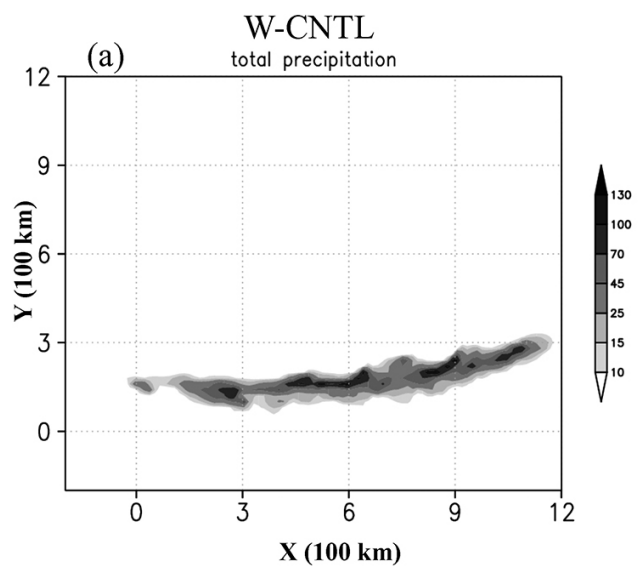

(b) The maximum of hourly precipitation

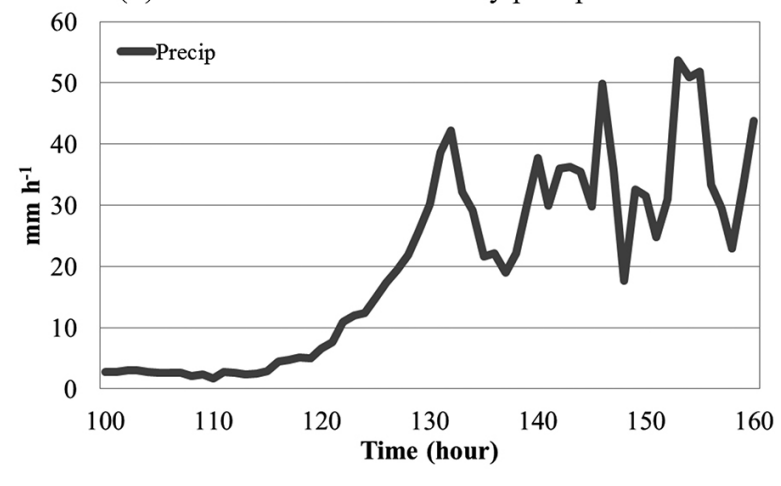

Fig. 3. (a) Horizontal distribution of total precipitation ( $\mathrm{mm}$ ) accumulated from $t=0$ to $160 \mathrm{~h}$ and (b) Evolution of the maximum of hourly precipitation $\left(\mathrm{mm} \mathrm{h}^{-1}\right)$ for the W-CNTL. 
precipitation exceeds $40 \mathrm{~mm} \mathrm{~h}^{-1}$ around $t=130 \mathrm{~h}$, and then the maximum precipitation of $20-50 \mathrm{~mm} \mathrm{~h}^{-1}$ is maintained until $t=160 \mathrm{~h}$ (Fig. 3b). These features of the precipitation are related to the environment in the western part of the Baiu frontal zone that is characterized by the large amount of water vapor. It is suggested that localized latent heating yielding the continuous large precipitation intensifies the W-BFD.

Low-level PV development for the W-CNTL is shown in Fig. 4. At $t=130 \mathrm{~h}$, a low-level high PV region forms around $x=-400 \mathrm{~km}, y=100 \mathrm{~km}$, corresponding to the center of the cyclonic circulation (Fig. 4a). After that time, it becomes enhanced and zonally elongated. At $t=160 \mathrm{~h}$, the region of high PV over 1 potential vorticity unit (PVU) extends from $x=200$ km to $900 \mathrm{~km}$ (Fig. 4d).
Figure 5 shows the evolution of a $300-\mathrm{hPa} \mathrm{PV}$ and geopotential height. At $t=130 \mathrm{~h}$, an upper-level high PV exceeding 1 PVU is located northwest of the low-level disturbance (Fig. 5a). The position of the upper-level high PV north of the cyclone center is associated with the upper-level jet stream located north of $y=0 \mathrm{~km}$ (not shown). After that, the high PV gradually increased from $t=150 \mathrm{~h}$ to $160 \mathrm{~h}$, and the maximum PV exceeds 1.2 PVU around $x=-500-500$ $\mathrm{km}$ and $y=500 \mathrm{~km}$ (Figs. 5c, d). As shown in the $\mathrm{PV}$ evolution, the evolution of $300-\mathrm{hPa}$ geopotential height also shows that an upper-level trough slightly develops from $t=130$ to $160 \mathrm{~h}$. Figure 5e shows the vertical-cross section of $\mathrm{PV}$ along line $\mathrm{A}-\mathrm{A}^{\prime}$ in Fig. 5d. Although the upper-level high PV exceeding 1 PVU is located at about $300 \mathrm{hPa}$ between -500 and

\section{0-hPa PV \& SLP for W-CNTL}

(a) $\mathrm{T}=130$
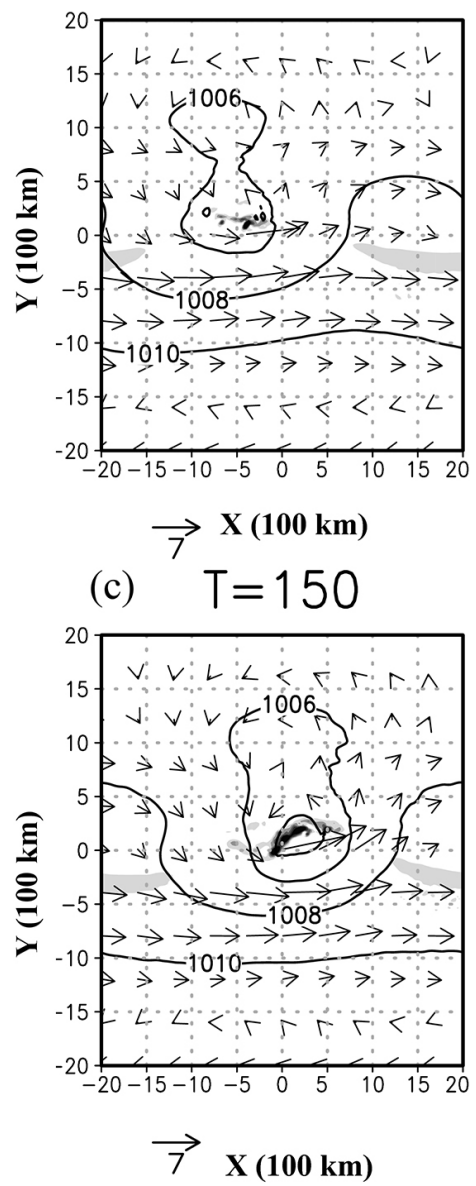

(b) $T=140$

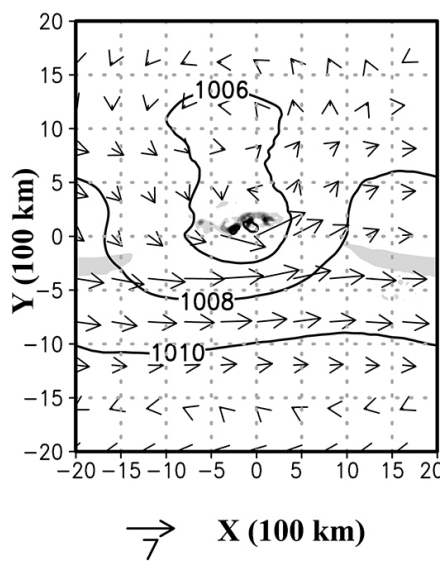

(d) $\mathrm{T}=160$

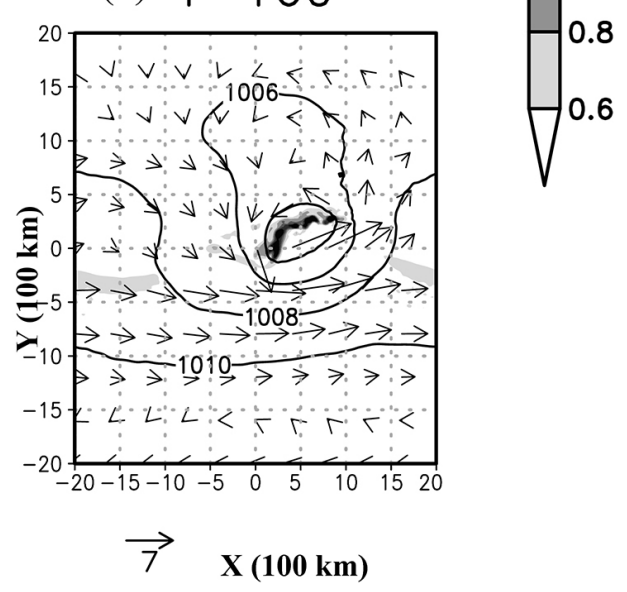

Fig. 4. Same as Fig. 2, but for $850-\mathrm{hPa}$ PV (shading; Potential Vorticity Units; 1 PVU $=10^{-6} \mathrm{~m}^{2} \mathrm{~s}^{-1} \mathrm{~K} \mathrm{~kg}^{-1}$ ). Vectors indicate $850-\mathrm{hPa}$ wind $\left(\mathrm{m} \mathrm{s}^{-1}\right)$. 
300-hPa PV \& height for W-CNTL

(a) $\mathrm{T}=130$

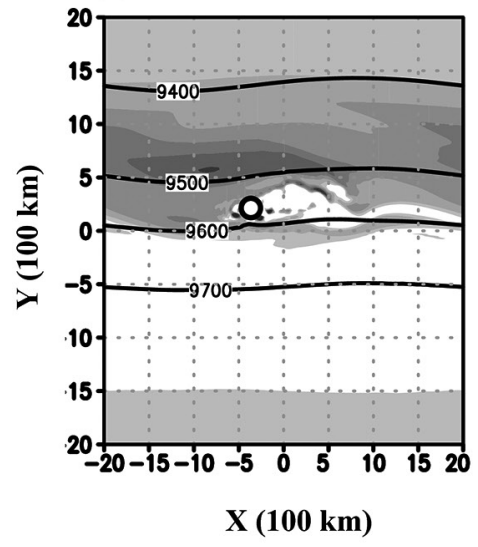

(c) $T=150$

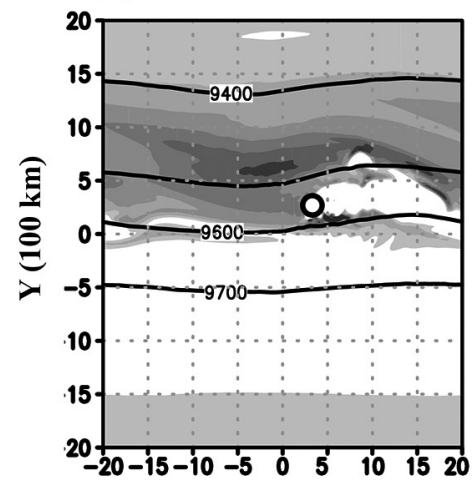

X (100 km) (b) $T=140$

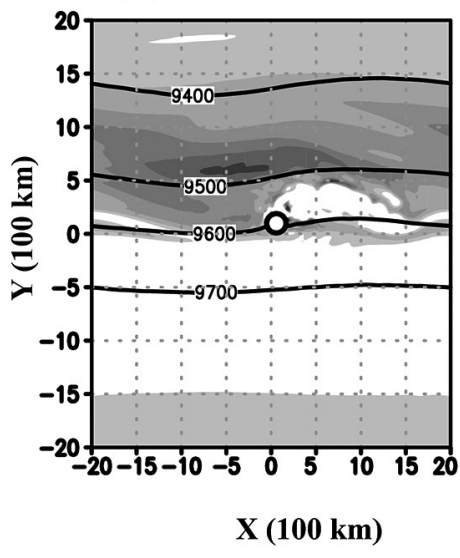

(d) $T=160$

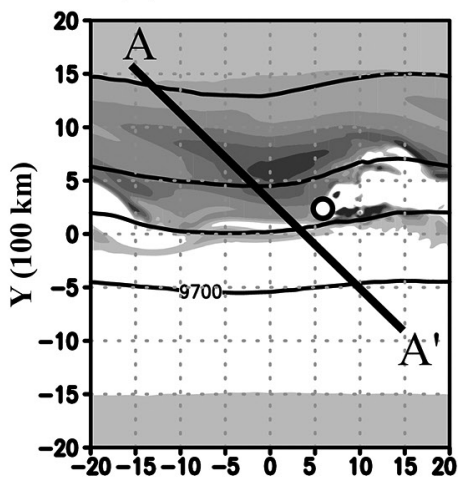

X (100 km)

(e)

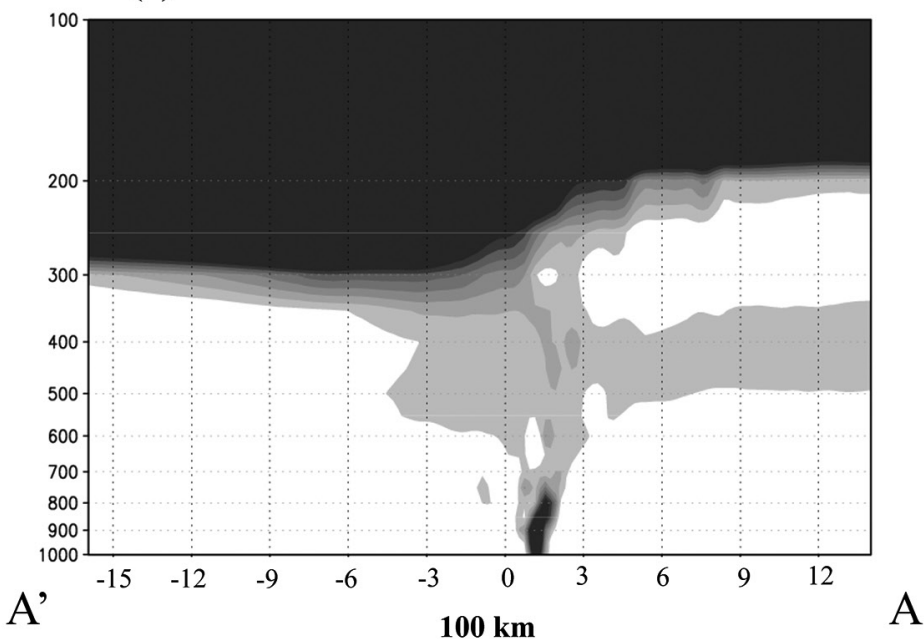

Fig. 5. (a)-(d) 300-hPa PV (shading; PVU) and geopotential height (contour lines; m) for the W-CNTL at (a) $t$ $=130 \mathrm{~h}$, (b) $t=140 \mathrm{~h}$, (c) $t=150 \mathrm{~h}$, and (d) $t=160 \mathrm{~h}$. Contour increment is $2 \mathrm{hPa}$. (e) Vertical-cross section of PV along $\mathrm{A}-\mathrm{A}^{\prime}$ line in (d). Circles in $(\mathrm{a}, \mathrm{b}, \mathrm{c}, \mathrm{d})$ indicate the positions of the cyclone center. 
$0 \mathrm{~km}$, it is hardly found that the downward intrusion of upper-level high PV. The lesser intrusion of high PV (around 0-200 km in Fig. 5e) compared with that in Part I could be due to the lack of a pre-existing upper-level trough in this idealized study.

The characteristics of the upper-level disturbance are somewhat different from those in Part I. Unlike Part I, there is no pre-existing upper-level trough in the idealized experiment, and the development of upper-level disturbance occurs only through interaction with the low-level depression as a baroclinic wave. Thus, the distance between upper- and lower-level disturbances in the idealized experiment is almost fixed throughout the developing stage, and is shorter than that in Part I. However, it seems that this difference is not essential to the W-BFD development as the amplitude of the upper-level trough in the idealized experiment is quite small.

\subsection{Vertical structure}

First, we describe the vertical structures of the geopotential height anomaly and updraft. Figures $6 \mathrm{a}$ and $6 \mathrm{~b}$ show their zonal-height cross sections through the W-BFD center during the developing stage. The region with large negative geopotential height anomalies is limited at low levels of the atmosphere. The low-level negative anomalies enhance with time; the minimum decreases from about $-20 \mathrm{~m}$ at $t=130 \mathrm{~h}$ to $-40 \mathrm{~m}$ at $t=160 \mathrm{~h}$. The structure of the negative anomalies is tilted westward with height throughout the troposphere, which is similar to a baroclinic wave-like structure. It should be noted that an almost upright structure is found under $700 \mathrm{hPa}$ around the depression center.

The position of the strong updraft relative to the cyclone center at which the geopotential height anomaly at low levels is minimum depends on the stage of W-BFD development (Figs. 6a, b). In the early stage $(t=130 \mathrm{~h})$, strong updrafts exceeding $0.5 \mathrm{~m} \mathrm{~s}^{-1}$ are located near the cyclone center. At $t=160 \mathrm{~h}$, strong updrafts extending from the low to upper levels are formed to the front $(x=800 \mathrm{~km})$ of the depression center (Fig. 6b).

The zonal-height cross sections of potential temperature (PT) and its anomaly through the W-BFD center are shown in Figs. 6c and 6d. The W-BFD has positive PT anomalies from the middle to upper levels of the atmosphere. At $t=130 \mathrm{~h}$, positive PT anomalies of around $2 \mathrm{~K}$ are found limitedly at middle level (approximately $500 \mathrm{hPa}$; Fig. 6c). These anomalies intensify with time and exceed $4 \mathrm{~K}$ at $t=160 \mathrm{~h}$ (Fig. $6 d)$.

\subsection{Effects of latent heating}

The contributions of latent heating and baroclinicity to the W-BFD development are investigated by an APE diagnosis. The APE tendency terms (refer to Eqs. $1-6$ in Part I) that are vertically integrated from 950 to $250 \mathrm{hPa}$ are shown in Fig. 7. Unlike Part I, each term is calculated in the entire model domain (4000 $\mathrm{km} \times 4000 \mathrm{~km}$ ) to avoid the dependence of results on the choice of calculation domains. The diabatic term (GE) is dominant throughout the development stage. Although the contribution of the baroclinic term (CA) increases with time, it is much smaller than the GE for the entire period. The values of CA and GE terms are smaller than those in Part I, since the domain for calculating APE terms in this study includes not only the area of the disturbance but also the outside area.

The $850-\mathrm{hPa}$ PV production rate, which is calculated using Eq. (7) in Part I, and wind fields in the W-BFD are shown in Fig. 8. At $t=130 \mathrm{~h}$, a high PV production region exceeding $2 \mathrm{PVU} \mathrm{h}^{-1}$ is located around $x=-400, y=100 \mathrm{~km}$, close to the depression center. At $t=160 \mathrm{~h}$, the region moves to the front (east) of the center. These features are consistent with those in the case-study W-BFD simulation (Part I). Meanwhile, a region of band-shaped PV production, which existed in Part I, is not found in the idealized experiment. This could be due to that the frontal zone east of the cyclone center is less intensified than Part I. The weaker frontal zone in the idealized experiment could be associated with the more meridionally smoothed basic field compared to Part I and small water vapor transport by a zonally inhomogeneous circulation such as a subtropical high.

The strength and horizontal structure of the BFD in the W-NOLH notably differ from those in the W-CNTL (Fig. 9). A central SLP (about $1006 \mathrm{hPa}$ ) is little lowered in the W-NOLH, while it falls to below $1003 \mathrm{hPa}$ in the W-CNTL. The localized updrafts exceeding $20 \mathrm{~cm} \mathrm{~s}^{-1}$ at $700 \mathrm{hPa}$ in the W-CNTL (Figs. 9a, b) are not found in the W-NOLH (Figs. 9c, d): wide-spreading updrafts with about $0.25 \mathrm{~cm} \mathrm{~s}^{-1}$ exist in the W-NOLH. Localized structure of the updrafts in the W-CNTL is due to small-scale strong convection. The strong updrafts in the W-CNTL are located near the depression center in the early stage, while they are found in front of the center in the later stage. In the W-NOLH, in contrast, the structure of upward (downward) motions located ahead (rear) of the low center resembles a baroclinic wave-like structure.

A comparison of the vertical geopotential height structures and vertical velocity also shows notable differences between the W-CNTL (Figs. 6a, b) and 


$$
\mathrm{T}=130 \quad \mathrm{~W}-\mathrm{CNTL} \quad \mathrm{T}=160
$$

$\begin{array}{ll}\text { (a) geopotential height anomaly \& W } & \text { (b) geopotential height anomaly \& W }\end{array}$

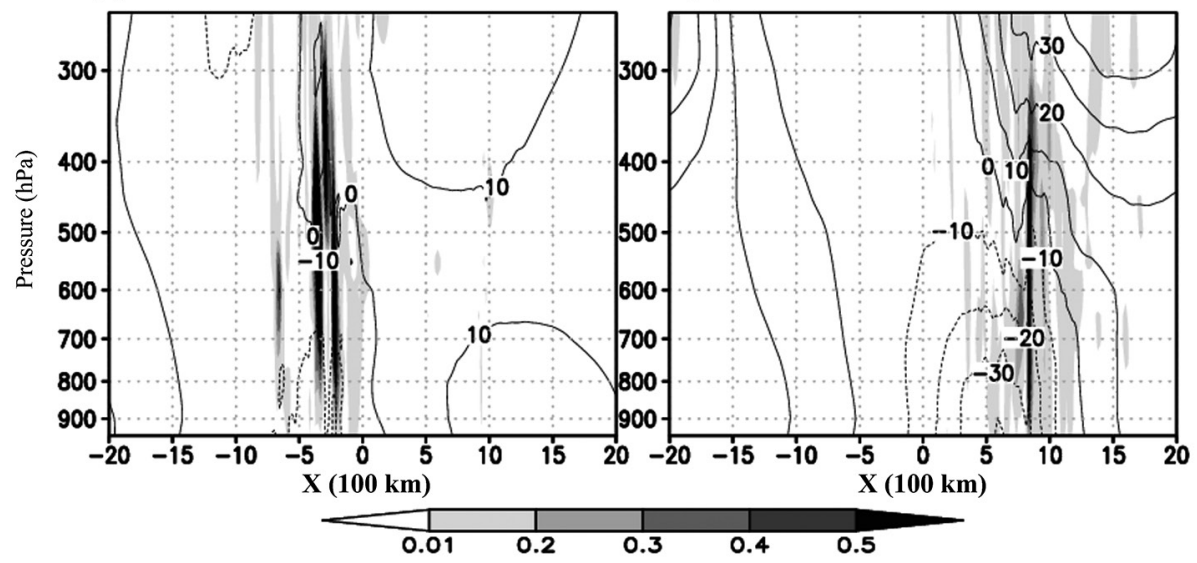

(c) $\mathrm{PT}$ anomaly \& PT

(d)

PT anomaly \& PT

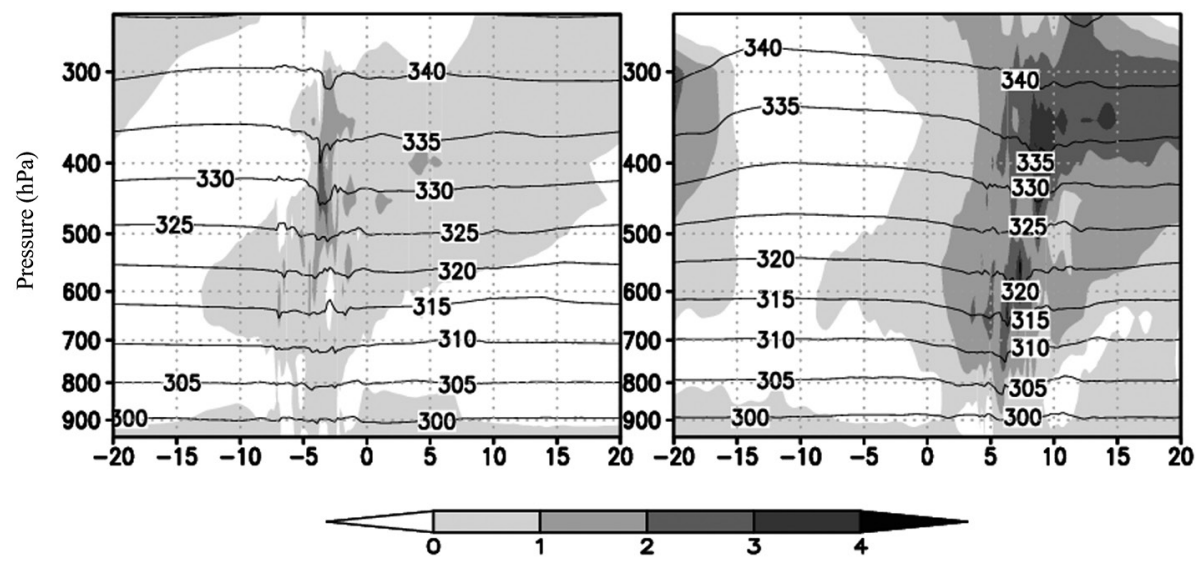

Fig. 6. Zonal-height cross sections of $(\mathrm{a}, \mathrm{b})$ vertical velocity (shading; $\mathrm{m} \mathrm{s}^{-1}$ ) and geopotential height anomaly (contour lines; $\mathrm{m}$ ), and (c, d) potential temperature (contour lines; K) and its anomaly (color shading; K) through the center of the W-CNTL at $(\mathrm{a}, \mathrm{c}) t=130 \mathrm{~h}$ and $(\mathrm{b}, \mathrm{d}) t=160 \mathrm{~h}$. Contour increment is $100 \mathrm{~m}^{2} \mathrm{~s}^{-2}$ for geopotential anomaly and $5 \mathrm{~K}$ for potential temperature. "W" on (a) and (b) indicate vertical velocity.

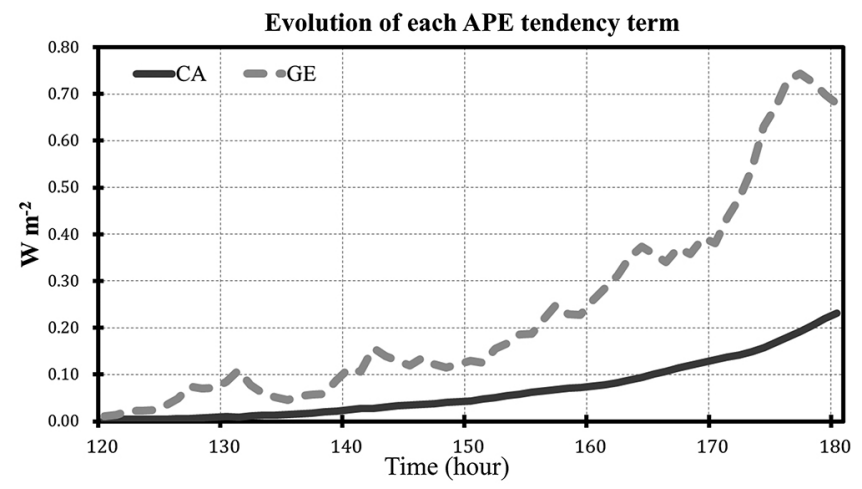

Fig. 7. Evolutions of each APE tendency term for the W-CNTL. Solid and dashed lines are CA and GE terms in Eqs. (1)-(6) in Part I. 


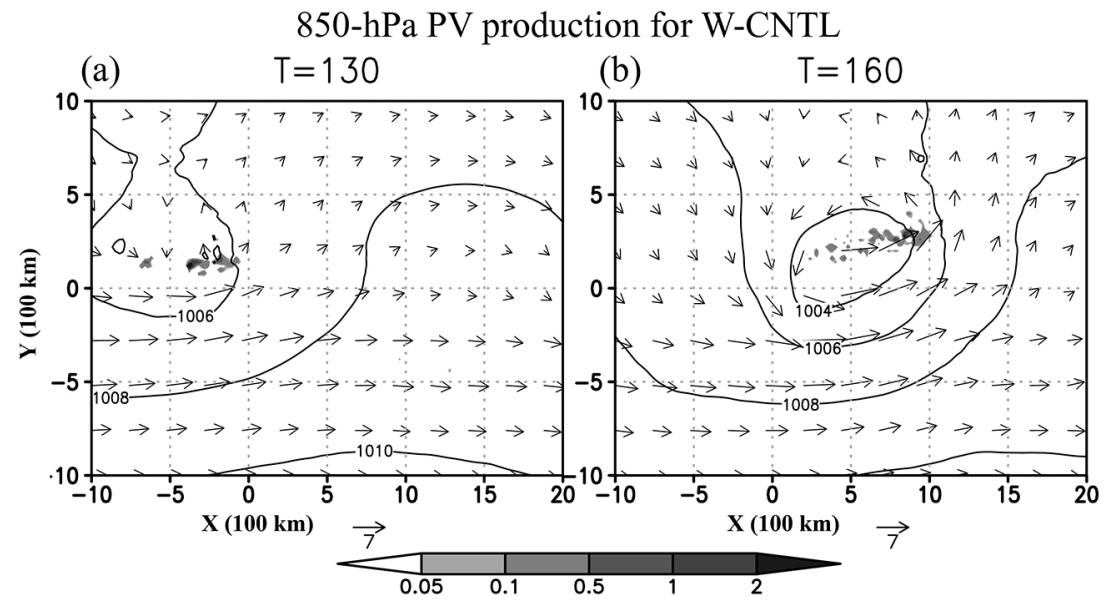

Fig. 8. 850-hPa PV production due to latent heating (shading; PVU $\mathrm{h}^{-1}$ ) and SLP (contour lines; $\mathrm{hPa}$ ) for the $\mathrm{W}-\mathrm{CNTL}$ at (a) $t=130 \mathrm{~h}$ and (b) $t=160 \mathrm{~h}$. Vectors indicate winds $\left(\mathrm{m} \mathrm{s}^{-1}\right)$ at $850 \mathrm{hPa}$. Contour increment is 2 $\mathrm{hPa}$.

(a) $W \&$ SLP $T=130$

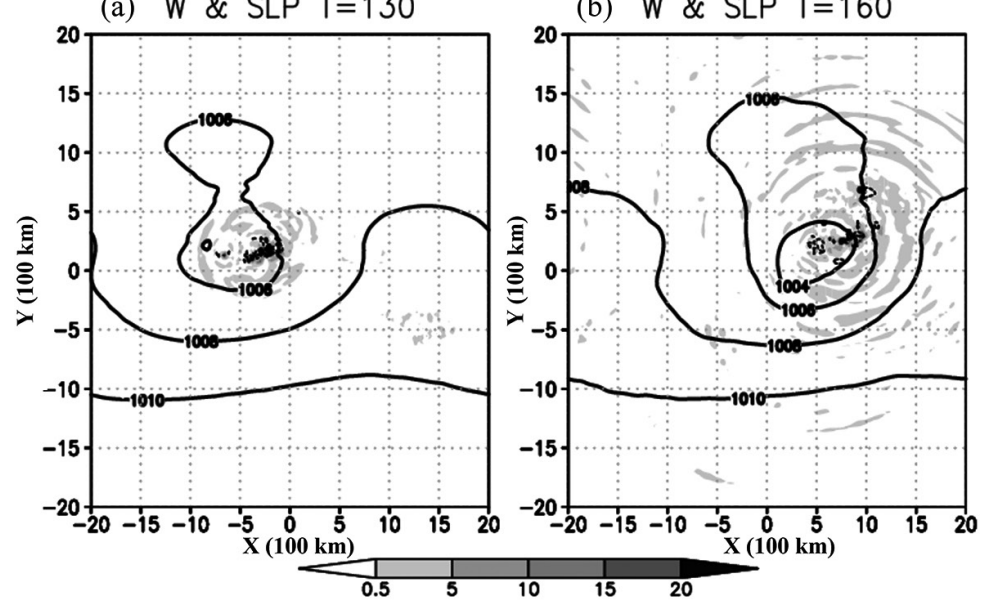

(c) $W$ \& SLP $T=130$

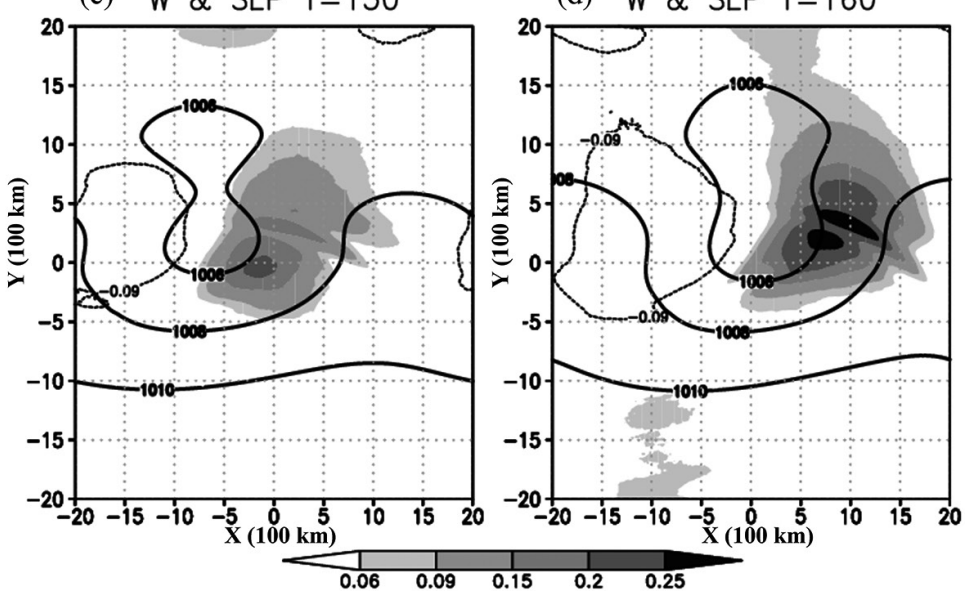

Fig. 9. 700-hPa vertical velocity (shading for positive and dashed for negative; $\mathrm{cm} \mathrm{s}^{-1}$ ) and SLP (contour lines; $\mathrm{hPa}$ ) for the $(a, b)$ W-CNTL and (c, d) W-NOLH at $(\mathrm{a}, \mathrm{c}) t=130 \mathrm{~h}$ and $(\mathrm{b}, \mathrm{d}) t=160 \mathrm{~h}$. Contour increment is $1 \mathrm{hPa}$. "W" on (a) and (b) indicates vertical velocity. 


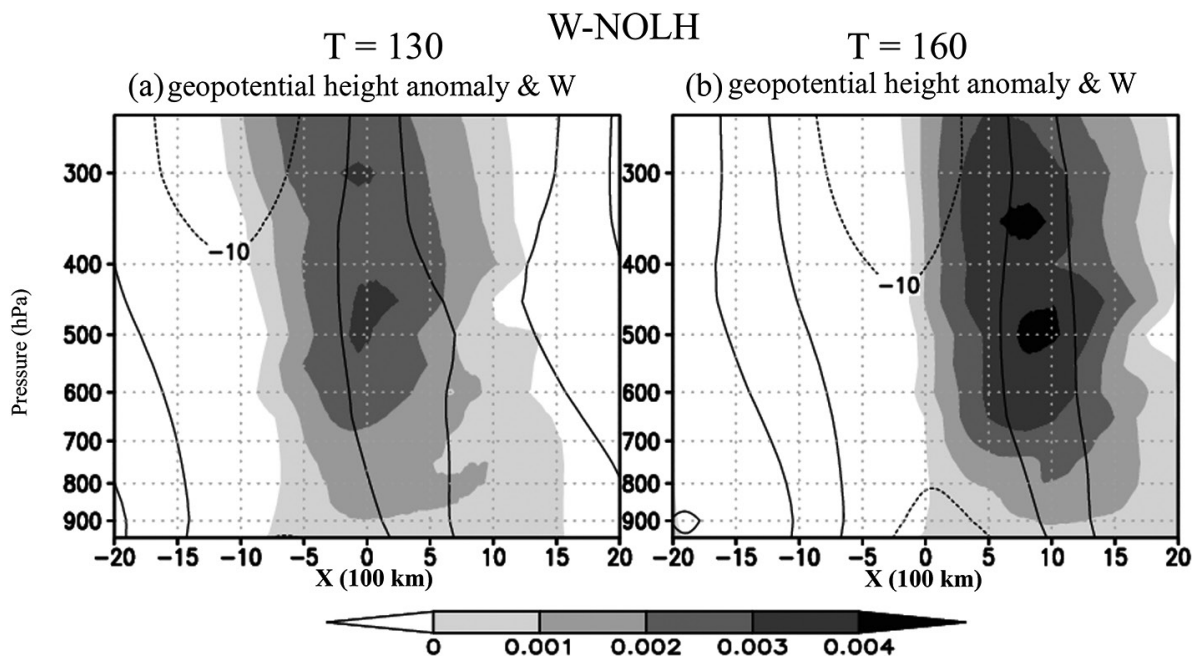

Fig. 10. Zonal-height cross sections of vertical velocity (shading; $\mathrm{m} \mathrm{s}^{-1}$ ) and geopotential height anomaly (contour lines; m) through the center of the W-NOLH (a) $t=130 \mathrm{~h}$ and (b) $t=160 \mathrm{~h}$.

W-NOLH (Fig. 10). The low-level negative height anomalies in the W-NOLH are notably smaller, indicating that latent heating largely contributes to the W-BFD development. In addition, W-NOLH also has baroclinic wave-like structures tilted westward through the troposphere (Figs. 6b, 10b), although it does not have the upright structure found at low levels around the depression center in the W-CNTL (Fig. $6 b)$. The fairly weak upward velocity in front of the cyclone center is maintained throughout the development stage in the W-NOLH.

\section{E-BFD}

\subsection{Evolution}

The evolutions of cloud system and SLP for the E-CNTL are first described in this section (Fig. 11). A depression located near $x=-1500 \mathrm{~km}$ is accompanied by a convective region extending from the north to east of the E-BFD center at $t=220 \mathrm{~h}$ (Fig. 11a). After that time, while propagating eastward, the E-BFD further develops and exhibits a comma-shaped cloud pattern by $t=280 \mathrm{~h}$ (Fig. 11d). Both the cloud system and the pressure field for the E-BFD exhibit structures similar to those for an extratropical depression (ED; Bader et al. 1995). As also found in the W-CNTL, the meridionally elongated structure of SLP, which is different from Part I, is found in the E-CNTL.

The characteristics of precipitation for the E-BFD differ from those for the W-BFD. In the E-CNTL (Fig. 12a), a wider area of precipitation between $y=$ $300 \mathrm{~km}$ and $y=1000 \mathrm{~km}$ and a smaller maximum of total precipitation of approximately $70 \mathrm{~mm}$ are found compared with those in the W-CNTL (Fig. 3a). The intensity of hourly maximum precipitation of approximately $20 \mathrm{~mm}$ (Fig. 12b) is weaker than approximately $50 \mathrm{~mm}$ for the W-CNTL (Fig. 3b). These features suggest that diabatic PV production associated with the precipitation system occurs over the wider area and its maxima are weaker compared with those in the W-CNTL. The precipitation associated with vertical motions around the warm front is found to the north and east of the cyclone center in the E-CNTL (Fig. $11)$.

The evolution of low-level PV is shown in Fig. 13. At $t=220 \mathrm{~h}$, a region of high PV exceeding $0.8 \mathrm{PVU}$ extends from $x=-3000$ to $-500 \mathrm{~km}$ around $y=500$ $\mathrm{km}$ (Fig. 13a). Here, $x=-3000 \mathrm{~km}$ corresponds to $x=$ $1000 \mathrm{~km}$ because of cyclonic boundary conditions in the $\mathrm{x}$-direction. This low-level high PV could be produced by latent heating with quite weak precipitation (Fig. 12b). As the time progresses, the low-level high $\mathrm{PV}$ is intensified from the north to the east of the cyclone center (Figs. 13b-d). This intensification of the low-level high PV is likely due to the latent heating yielding the convection (Fig. 11). At $t=280 \mathrm{~h}$, a high $\mathrm{PV}$ region with a length exceeding $1500 \mathrm{~km}$ forms around the cyclone (Fig. 13d).

The upper-level disturbance for the E-BFD, which has a larger amplitude compared with that for the W-BFD (Fig. 5), is located west of the low-level cyclone center throughout the developing stage (Fig. 14). At $t=220 \mathrm{~h}$, the region of $300-\mathrm{hPa}$ high $\mathrm{PV}$ 


\section{E-CNTL}

(a) $\mathrm{T}=220$

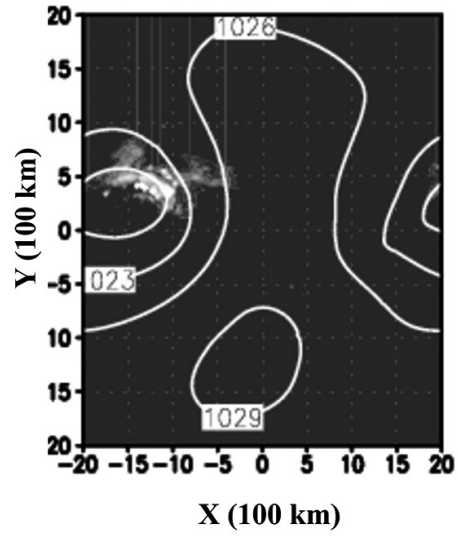

(c) $T=260$

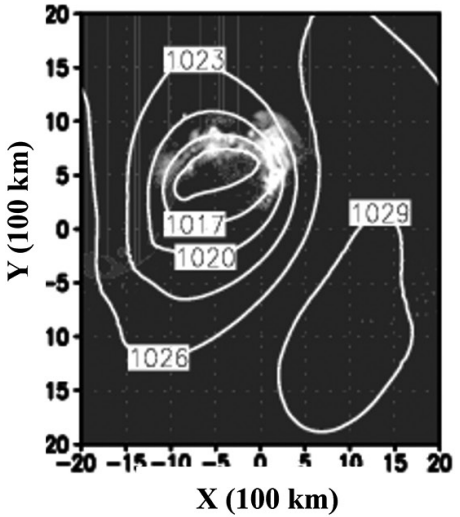

(b) $T=240$

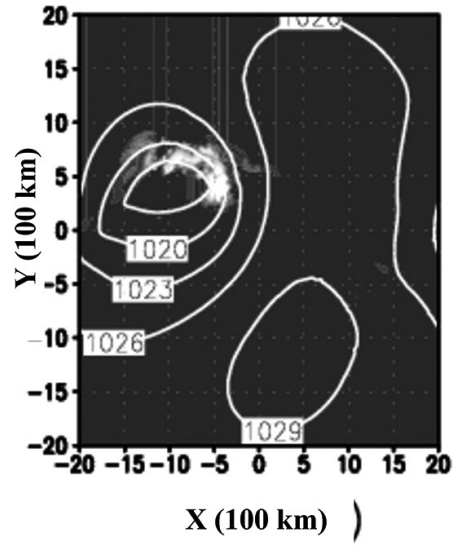

(d) $\quad T=280$

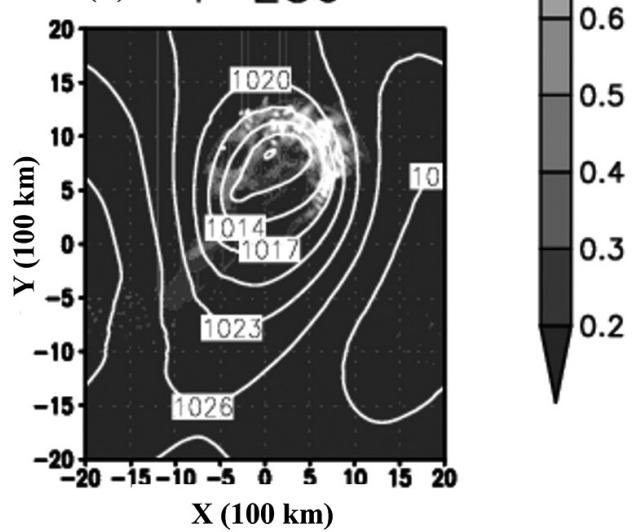

Fig. 11. Same as Fig. 2 except for the E-CNTL at (a) $t=220 \mathrm{~h}$, (b) $t=240, \mathrm{~h}$ (c) $t=260 \mathrm{~h}$, and (d) $t=280 \mathrm{~h}$. Contour increment is $3 \mathrm{hPa}$.

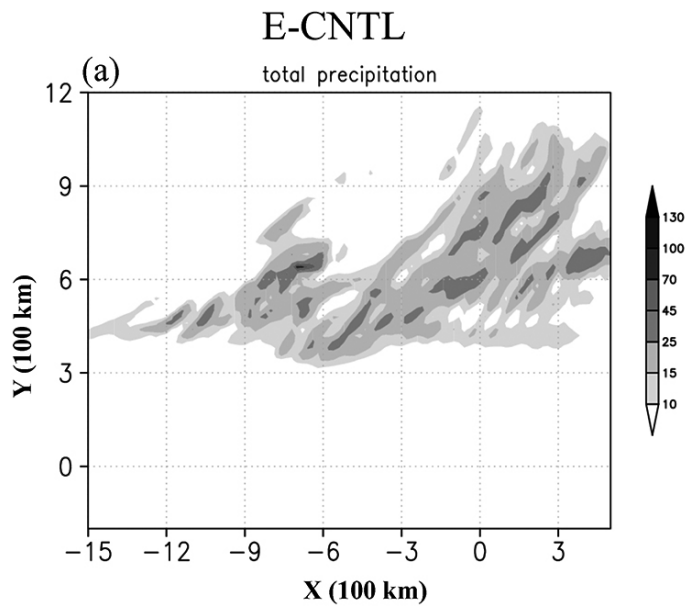

(b) The maximum of hourly precipitation

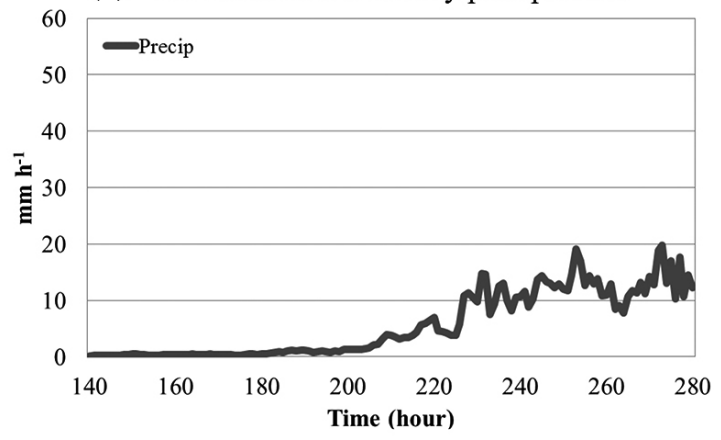

Fig. 12. Same as Fig. 3 except for the E-CNTL between $t=140$ and $280 \mathrm{~h}$. 


\section{0-hPa PV \& SLP for E-CNTL}

(a) $T=220$

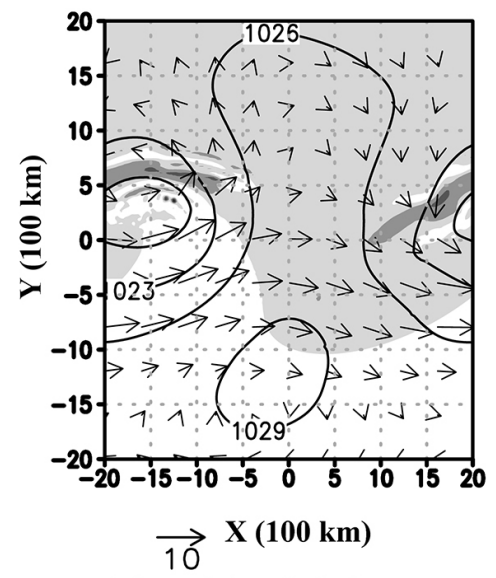

(c) $T=260$

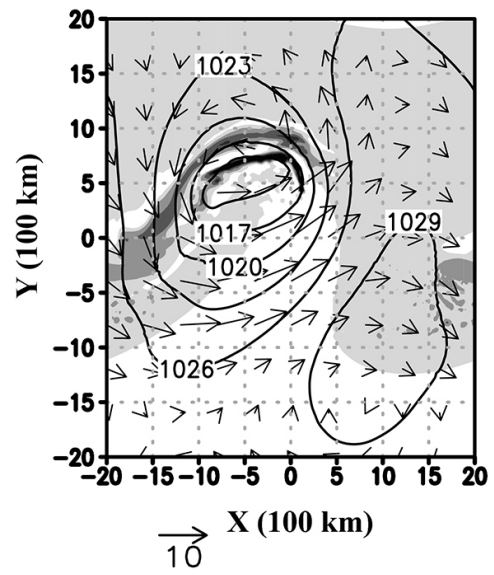

(b) $\mathrm{T}=240$

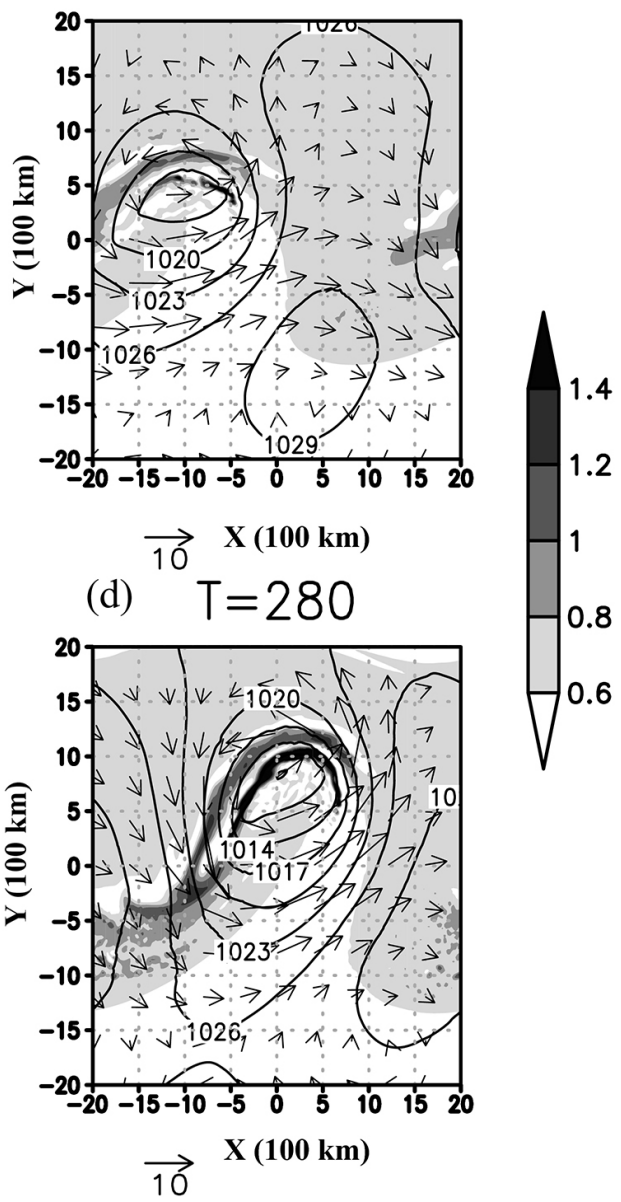

Fig. 13. Same as Fig. 4 except for the E-CNTL at $t=$ (a) $220 \mathrm{~h}$, (b) $240 \mathrm{~h}$, (d) $260 \mathrm{~h}$, and (e) $280 \mathrm{~h}$.

exceeding 1.3 PVU is located west of the low-level disturbance (Fig. 14a). The upper-level high PV propagates eastward and becomes wrapped up cyclonically on the west side of the low-level disturbance by $t=$ 280 h (Figs. 14b-d). This suggests that the interaction between the upper- and low-level disturbances is important to the E-BFD development. The evolution of upper-level geopotential height also indicates that the upper-level trough develops more deeply than that in the W-CNTL. The vertical-cross section of PV along the $\mathrm{B}-\mathrm{B}^{\prime}$ line in Fig. 14d shows the intrusion of the upper-level high PV exceeding 1 PVU from the upper levels to about $350-400 \mathrm{hPa}$ on the west side of the E-BFD between -600 and $-200 \mathrm{~km}$ (Fig. 14e). This intrusion is smaller than that in Part I, since there is no pre-existing trough in this idealized study.

\subsection{Vertical structure}

The vertical structure in the zonal direction through the E-BFD center is examined in this subsection. The geopotential height anomaly field for the E-BFD exhibits a westward-tilted structure with height, which is consistent with the structure of a baroclinic wave in Eady's theory (Eady 1949; Figs. 15a, b). The westward tilt of the trough is larger than that for the W-BFD, which more clearly shows features of a typical baroclinic wave. Peaks of negative anomalies are found at both the upper and lower levels. At $t=280 \mathrm{~h}$, the upper- and low-level negative anomalies exceed $-50 \mathrm{~m}$ and $-120 \mathrm{~m}$, respectively.

The evolution of updrafts for the E-BFD differs from that for the W-BFD. The vertical structures of vertical velocity for the E-BFD at $t=230$ and $280 \mathrm{~h}$ 

300-hPa PV \& height for E-CNTL

(a) $\mathrm{T}=220$

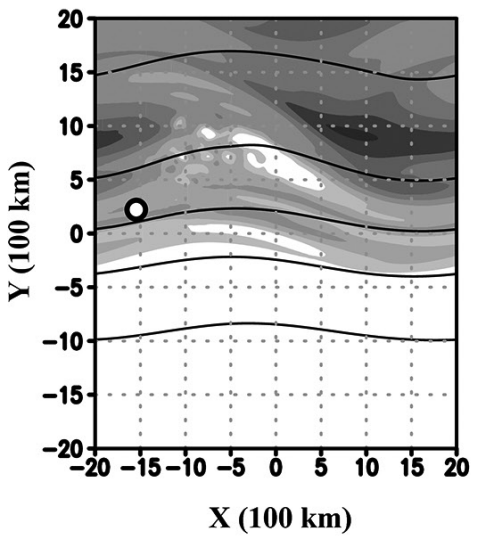

(c) $T=260$

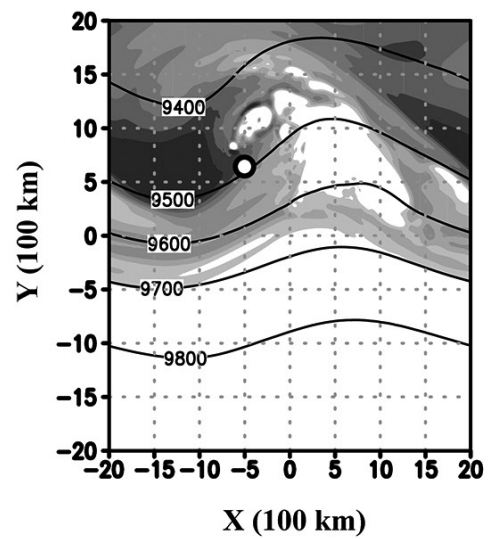

(e) (b) $\quad T=240$

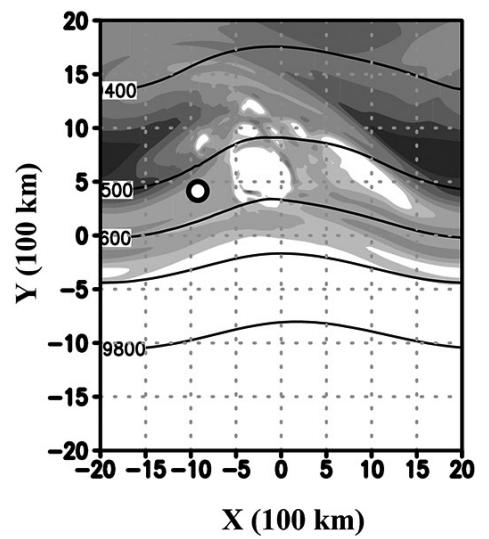

(d) $\mathrm{T}=280$

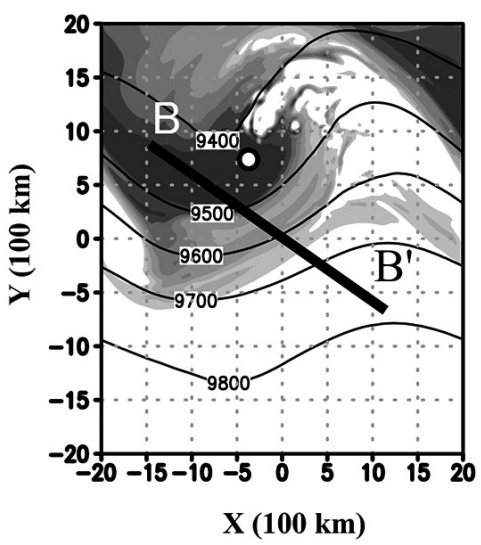

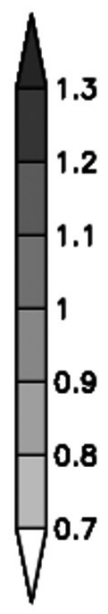

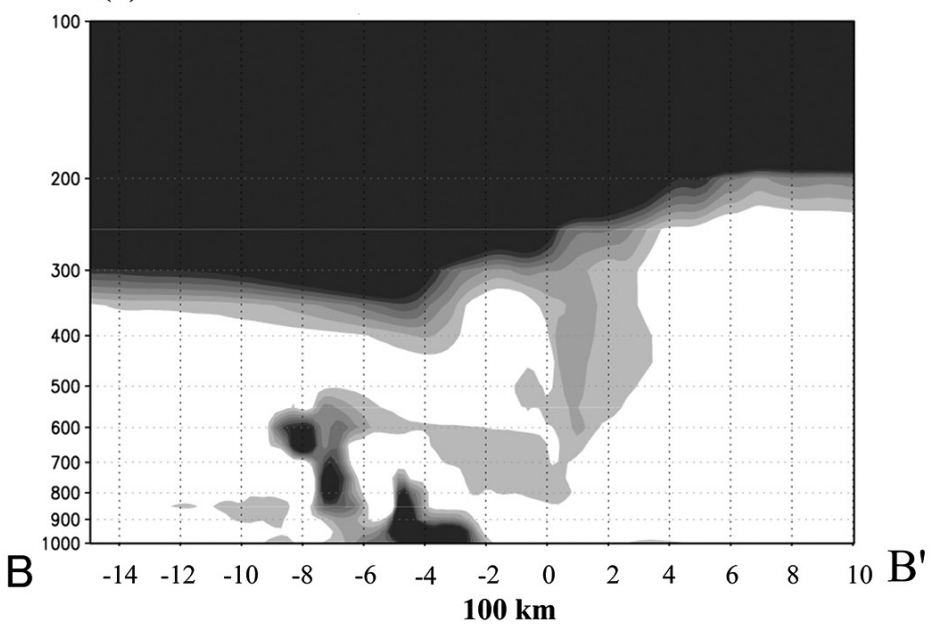

Fig. 14. Same as Fig. 5 except for the E-CNTL at $t=$ (a) $220 \mathrm{~h}$, (b) $240 \mathrm{~h}$, (d) $260 \mathrm{~h}$, and (e) $280 \mathrm{~h}$. (e) Verticalcross section of PV along B-B' line in (d). 

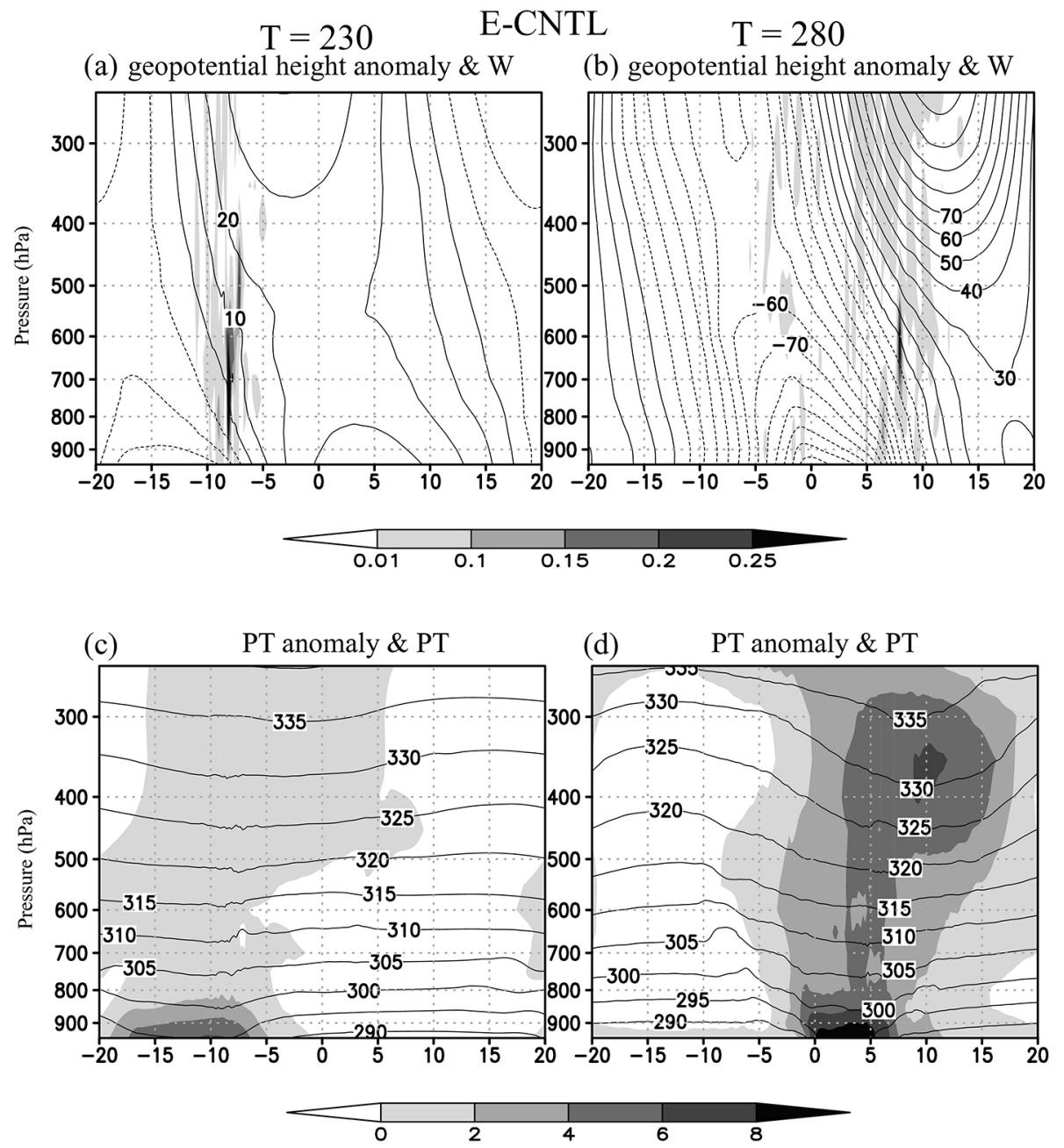

Fig. 15. Same as Fig. 6 except for the E-CNTL at (a, c) $t=230 \mathrm{~h}$ and (b, d) $t=280 \mathrm{~h}$.

are shown in Figs. 15a, b, respectively. Updrafts about $0.25 \mathrm{~m} \mathrm{~s}^{-1}$ are located in front of the low-level depression center throughout the development stage.

The thermodynamic structures of the E-BFD at $t$ $=230$ and $280 \mathrm{~h}$ are shown in Figs. $15 \mathrm{c}$ and $15 \mathrm{~d}$, respectively. The positive PT anomalies associated with the E-BFD are notably large at low levels and tilted eastward with height, which also indicates a baroclinic wave-like structure. The maximum amplitude exceeds $6 \mathrm{~K}$ at $t=230 \mathrm{~h}$ (Fig. 15c), then it intensifies with time and exceeds $8 \mathrm{~K}$ at $t=280 \mathrm{~h}$ (Fig. 15d).

\subsection{Effects of latent heating}

We describe the effects of latent heating for the E-BFD. The APE diagnosis shows that both diabatic heating and baroclinicity are important energy sources for the development (Fig. 16). The contributions of $\mathrm{CA}$ and GE are comparable through the developing stage. The values of CA and GE terms are larger than those in the W-CNTL as the fraction of the area associated with the E-BFD to the whole domain is larger than that of the W-BFD (Figs. 4d, 13d).

We focus on the PV production by latent heating for the E-BFD in the developing period. Unlike the W-BFD, the position of the low-level high PV production in the E-BFD does not change during the development stage (Fig. 17). At $t=230 \mathrm{~h}$, a PV production region is located in front (east) of the center of the cyclonic circulation (Fig. 17a). At $t=280 \mathrm{~h}$, the region extends in the meridional direction on the eastern side of the circulation center (Fig. 17b). This result is consistent with the case-study simulation (in 


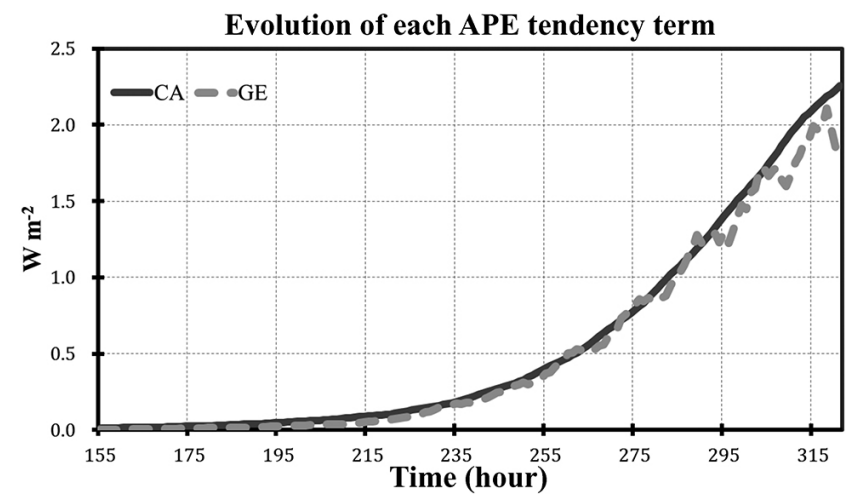

Fig. 16. Same as Fig. 7 except for the E-CNTL. Solid and dashed lines are CA and GE terms in Eqs. (1)-(6) in TK16.

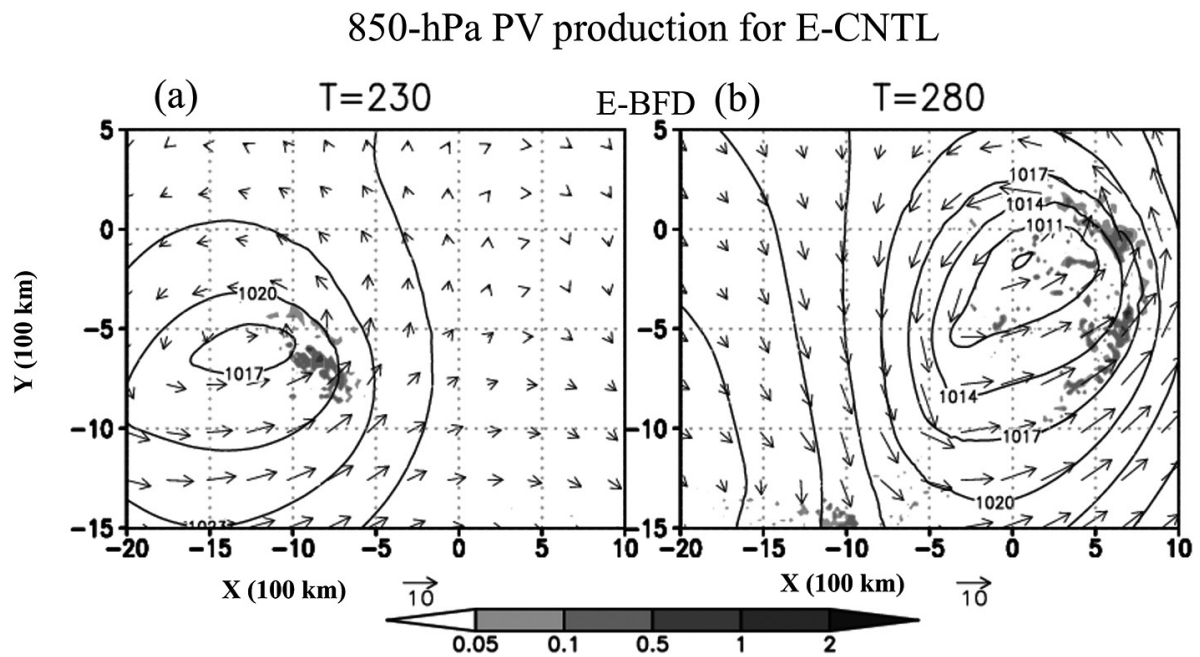

Fig. 17. Same as Fig. 8, except for the E-CNTL at (a) $t=230 \mathrm{~h}$ and (b) $t=280 \mathrm{~h}$. Note that contour increment is $3 \mathrm{hPa}$, and the area presented is between $x=-2000 \mathrm{~km}$ and $x=1000 \mathrm{~km}, y=-1500 \mathrm{~km}$ and $y=500 \mathrm{~km}$.

Part I).

A comparison between the E-CNTL and E-NOLH shows that both simulated E-BFDs have similar structures, but their strengths are different (Fig. 18). The SLP pattern and its associated updrafts (downdrafts) ahead (rear) of the depression center are similar between the E-CNTL and E-NOLH. However, the central SLP in the E-CNTL (about $1008 \mathrm{hPa}$ at $t=280 \mathrm{~h}$ ) is lower than that in the E-NOLH (about $1014 \mathrm{hPa}$ at $t=280 \mathrm{~h}$ ). From north to east of the depression center, there are strong and localized convective updrafts in the E-CNTL, constituting a comma-shaped cloud system.

A comparison of the vertical structures between the E-CNTL (Figs. 15a, b) and E-NOLH (Fig. 19) also indicates that latent heating little contributes to the structure of the E-BFD but to its development. The westward-tilted structures with height in both the E-CNTL and E-NOLH suggest that the E-BFD can develop through the baroclinic process. In addition, latent heating intensifies the negative geopotential height anomalies in the E-CNTL. It is also clear that positive anomalies at upper levels in the E-CNTL (Figs. 15a, b, 19) are intensified by latent heating. This feature may be due to the horizontal divergence associated with active convection. The weaker upward velocity in the E-NOLH is attributed to a lack of convection yielding cloud systems. Moreover, the result 


\section{E-CNTL}

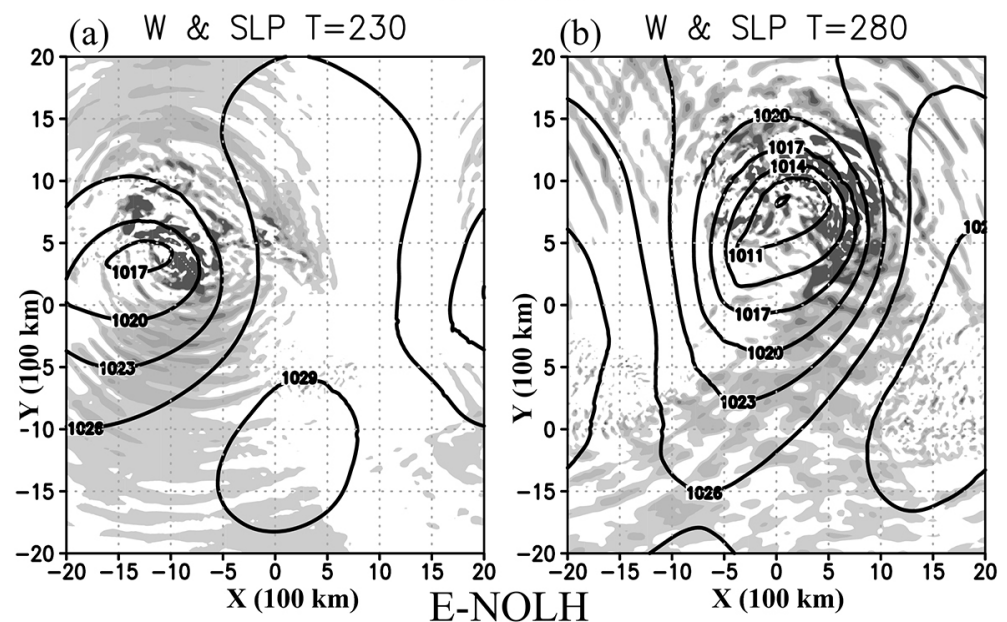

(c) $W \&$ SLP $T=230$

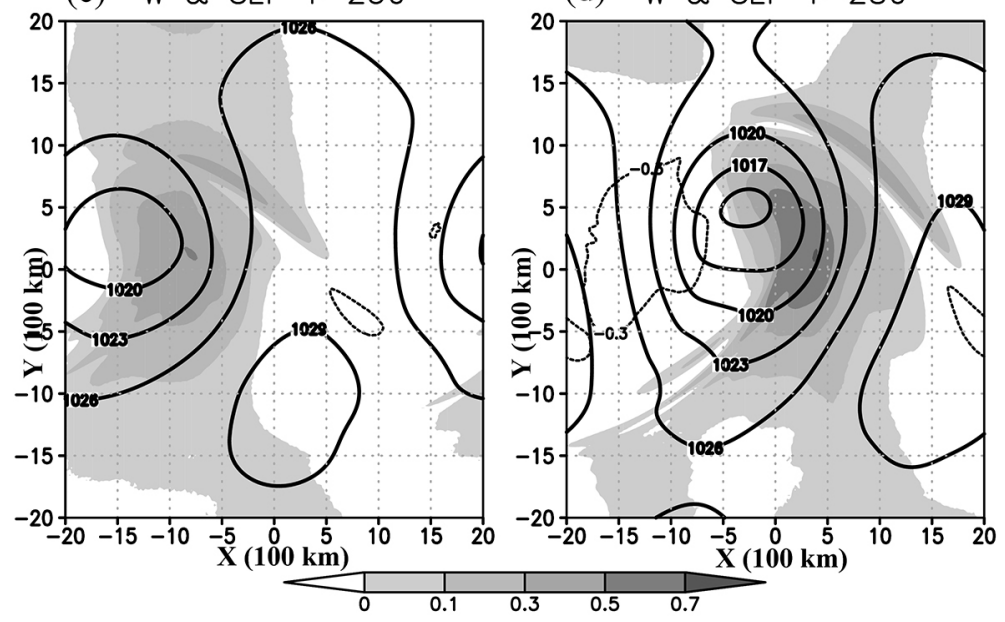

Fig. 18. Same as Fig. 9 except for the E-CNTL and E-NOLH at $(\mathrm{a}, \mathrm{c}) t=$ $230 \mathrm{~h}$, and (b, d) $t=280 \mathrm{~h}$. Contour increment for SLP is $2 \mathrm{hPa}$.

\section{$\mathrm{T}=230$}

E-NOLH

$\mathrm{T}=280$

(a) geopotential height anomaly \& W

(b) geopotential height anomaly \& W

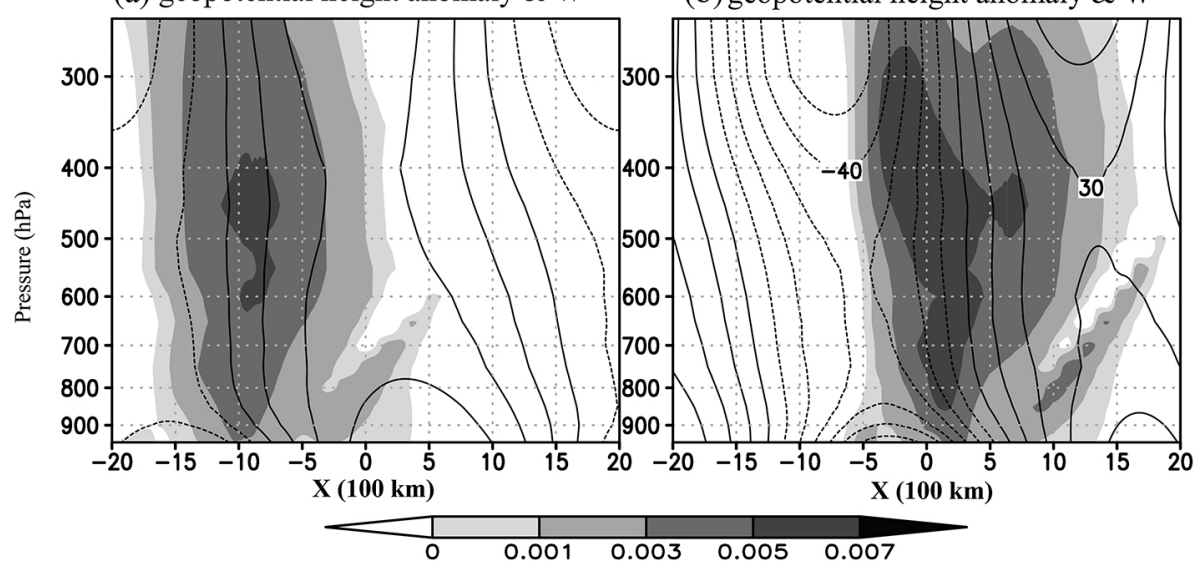

Fig. 19. Same as Fig. 10, except for the E-NOLH at (a) $t=230 \mathrm{~h}$, and (b) $t=280 \mathrm{~h}$. 
that the vertical velocities for the E-NOLH are notably stronger than those for the W-NOLH (Figs. 10a, b, $19 \mathrm{a}, \mathrm{b})$ indicates a larger contribution of baroclinicity to the E-BFD development.

\section{Discussion}

We discuss the development mechanisms of the W-BFD and E-BFD. The W-BFD has a development mechanism driven by latent heating. Figure 20 shows

W-CNTL

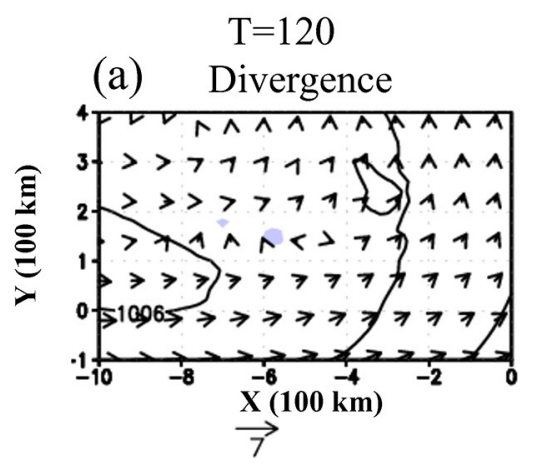

$\mathrm{T}=125$

(b) Divergence

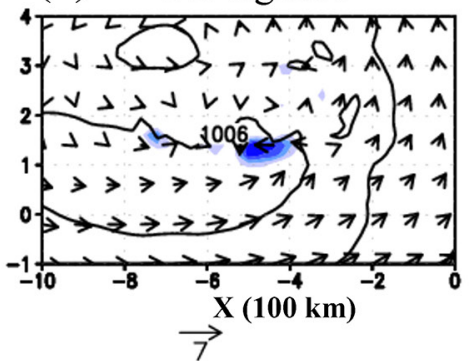

\begin{tabular}{ll|l|l|l} 
& & & & \\
\hline-1.2 & -0.9 & -0.6 & -0.3
\end{tabular}

(d) Latent heating

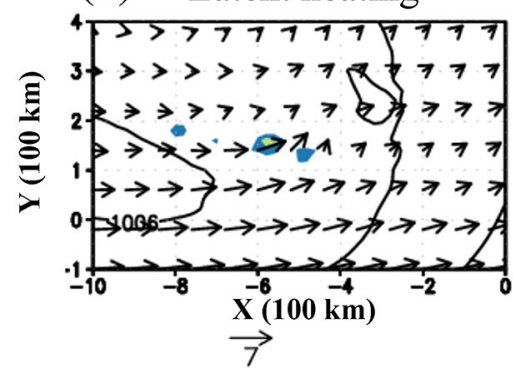

(e) Latent heating

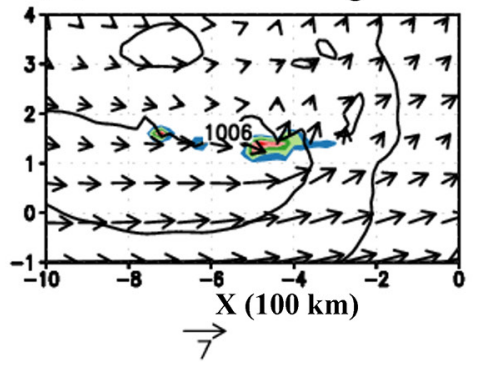

(f) Latent heating

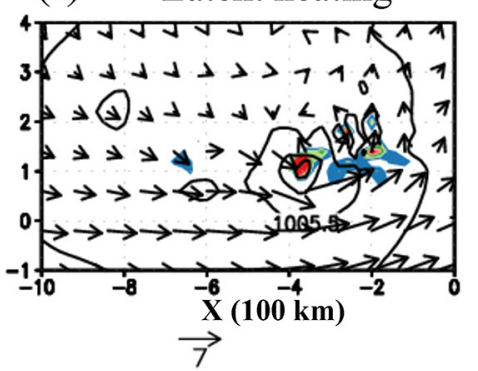

(c) Divergence

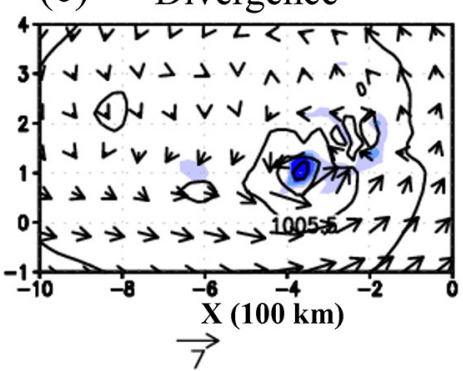

\section{\begin{tabular}{cc|c|cc|c|c}
$\mathcal{C}_{0.0002}$ & 0.0006 & 0.001 & & 1 \\
\hline
\end{tabular}}

(g) $\quad 850-\mathrm{hPa} \mathrm{PV}$

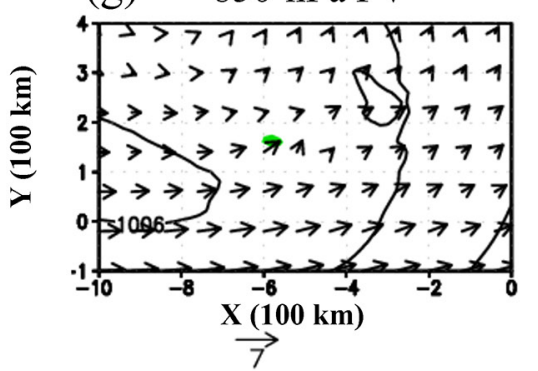

(h) $850-\mathrm{hPa} \mathrm{PV}$

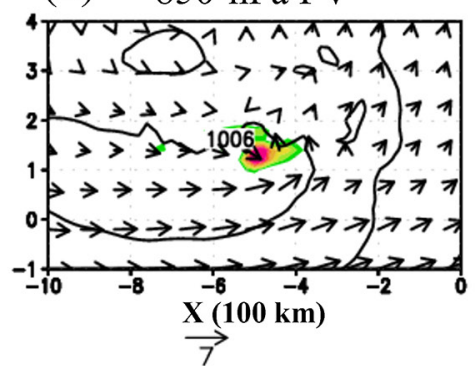

(i)

850-hPa PV

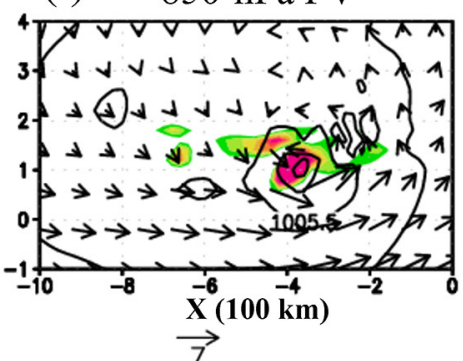

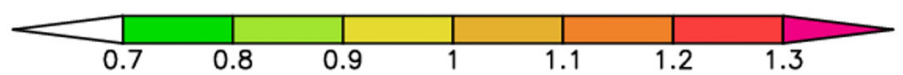

Fig. 20. (a)-(c) 950-hPa horizontal divergence (color shading; $10^{-4} \mathrm{~s}^{-1}$ ), (d)-(f) 850-hPa latent heating (color shading; $\mathrm{K} \mathrm{s}^{-1}$ ), and (g)-(i) 850-hPa PV (color shading; PVU) for the W-CNTL at (a, c, g) $t=120 \mathrm{~h},(\mathrm{~b}, \mathrm{e}, \mathrm{h}$ ) $t=125 \mathrm{~h}$, and $(\mathrm{c}, \mathrm{f}, \mathrm{i}) t=130 \mathrm{~h}$. Vectors indicate winds $\left(\mathrm{m} \mathrm{s}^{-1}\right)$ at each level. Contour lines indicate SLP drawn at $0.5 \mathrm{hPa}$ intervals. 
the 950-hPa horizontal divergence, $850-\mathrm{hPa}$ latent heating, and $850-\mathrm{hPa}$ PV fields in the early development stage. At $t=120 \mathrm{~h}$, when convection is started to be activated, these elements are not intensified yet. After that time, their values increase rapidly. The rapid intensification could be brought about by the following positive feedback: a weak baroclinic disturbance induces low-level convergent flows and thus causes cumulus convection. After that, latent heating associated with the convection generates a drop in pressure. The pressure gradient force toward low pressure, in turn, intensifies the low-level convergence resulting in the enhancement of active convection. As a result, rapid intensification of the low-level PV occurs near the cyclone center in the early development stage. The mechanism is consistent with the nonlinear conditional instability of the second kind (Cho and Chen 1995) discussed in Part I.

In the later stage, warm and moist air is advected to the front (east) of the depression by its associated southerlies or southwesterlies (Fig. 21a). In addition, the advection intensifies the low-level PT gradient in front of the W-BFD center at $t=160 \mathrm{~h}$ (Fig. 21b). This intensification of baroclinicity causes updrafts. This process is similar to the diabatic Rossby vortex mechanism (Raymond and Jiang 1990; Snyder and Lindzen 1991; Parker and Thorpe 1995; Moore and Montgomery 2004, 2005; Moore et al. 2008, 2013), which was also discussed in Part I.

The development mechanism of the W-BFD can be summarized as follows. In the early stage, convergent flows related to a depression cause convection near its center. In that stage, however, the production of the low-level PV in front of the cyclone center cannot occur because low-level baroclinicity is too weak to force enough upward motion to initiate convection. As the vortex develops, southerlies or southwesterlies are enhanced in front (east) of the W-BFD center. As there is a large amount of water vapor south of the Baiu frontal zone, the southerlies or southwesterlies advect warm and moist air from the south to the east (front) of the center. In addition, the meridional temperature gradient is enhanced there as the W-BFD develops. As a consequence, both active convection and its associated PV production occur in front (east) of the center in the later stage (Figs. 2, 8).

In contrast, the E-BFD develops through the baroclinic process in the moist atmosphere. The E-BFD has the structure similar to typical ED-like aspects and extracts large eddy APE from the basic fields as baroclinicity is larger than that for the W-BFD (Fig. 1). In addition, latent heating largely contributes to the E-BFD development as illustrated by both the APE diagnosis and the E-NOLH experiment. The baroclinicity and the amount of water vapor in the environments for the E-BFD are, respectively, smaller and larger compared with those in ordinary frontal zones in other seasons, which also indicates that both baroclinicity and latent heating are important to the development of the E-BFD.

W-CNTL
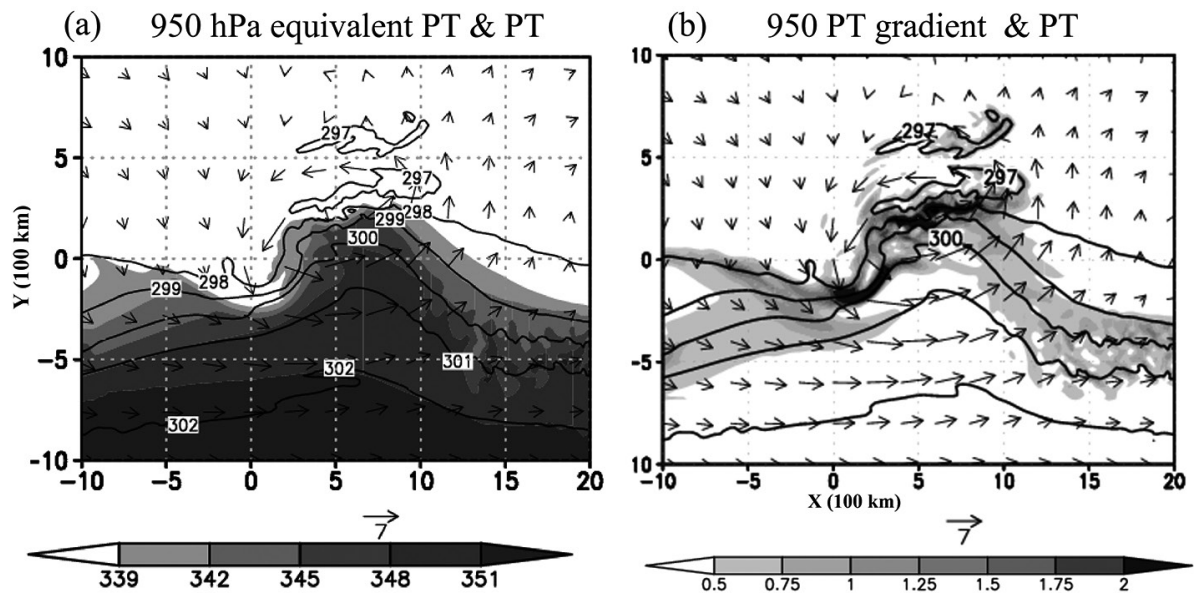

Fig. 21. (a) Equivalent potential temperature (color shading; K) and potential temperature (contour lines; K) at $950 \mathrm{hPa}$ for the W-CNTL at $t=160 \mathrm{~h}$. (b) The magnitude of potential temperature gradient (color shading; K $(100 \mathrm{~km})^{-1}$ ) and potential temperature (contour lines; K) at $950 \mathrm{hPa}$ for the W-CNTL at $t=160 \mathrm{~h}$. Wind fields $\left(\mathrm{m} \mathrm{s}^{-1}\right)$ are plotted by vectors. Contour increment is $1 \mathrm{~K}$. 


\section{Conclusions}

In this study, idealized numerical simulations with zonally homogeneous environments for the W-BFD and E-BFD, as classified by TK12, have been conducted to obtain a more generalized perspective of the effects of latent heating and baroclinicity on the BFD development and to confirm the development mechanisms of BFDs mentioned in Part I. The control simulations (CNTLs) with zonally homogeneous environments for the W-BFD and E-BFD produced a realistic W-BFD and E-BFD, respectively. This suggests that the basic fields for the W-CNTL and E-CNTL used in this study are typical environments in which W-BFDs and E-BFDs develop, respectively.

The vertical structures of the simulated BFDs are different between the W-CNTL and E-CNTL. The slightly westward-tilted vertical structure in the W-BFD is modulated by latent heating at low levels. In contrast, the vertical structure of the E-BFD is similar to an Eady's baroclinic wave amplified by latent heating.

The contributions of latent heating and baroclinicity to the BFD development have been examined by an APE diagnosis. The major contributor to the W-BFD development is latent heating, while the contribution from baroclinicity is small. In contrast, baroclinicity as well as latent heating largely contributes to the E-BFD development. These findings are consistent with the results from case-study numerical simulations described in Part I.

A comparison between the CNTL and the simulation without latent heating (NOLH) illustrates that latent heating plays a central role in the development of the W-BFD. The development of both the W-BFD and E-BFD is weakened in the NOLH. In addition, the BFD structure in the W-NOLH is quite different from that in the W-CNTL. In contrast, the structure of E-BFD, which tilts westward with height, hardly changes in the E-NOLH.

Several issues for the idealized numerical experiments remain in this study. The development of BFDs in the experiments is much later than that of the observed BFDs because zonally homogeneous and meridionally smoothed composite fields are used for the basic fields. In addition, this study has neglected the effects of pre-existing upper-level PV anomalies, although they contribute to the development of BFDs, as shown in Part I. Thus, to obtain further understanding of the dynamics of BFDs, it may be worthwhile to perform idealized numerical studies that solve these issues. Moreover, a set of sensitivity experiments of baroclinicity and the amount of low-level water vapor will provide helpful insight to the BFD development.

\section{Acknowledgments}

We would like to thank Profs. H. Itoh and R. Kawamura of Kyushu University, Prof. H. Niino and Dr. W. Yanase of the Atmosphere and Ocean Research Institute, the University of Tokyo, and Dr. A. Yamazaki of Japan Agency for Marine-Earth Science and Technology for their useful comments. We are grateful to Dr. T. Kato and two anonymous reviewers for their constructive comments. This work was supported by JSPS KAKENHI Grant Number 25400466.

\section{References}

Akiyama, T., 1984: A medium-scale cloud cluster in a Baiu front. Part I: Evolution process and fine structure. $J$. Meteor. Soc. Japan, 62, 485-504.

Akiyama, T., 1990a: Large, synoptic and meso scale variations of the Baiu front during July 1982. Part II: Frontal structure and disturbances. J. Meteor. Soc. Japan, 68, 557-574.

Akiyama, T., 1990b: Large, synoptic and meso scale variations of the Baiu front, during July 1982. Part III: Space-time scale and structure of frontal disturbance. J. Meteor. Soc. Japan, 68, 705-727.

Bader, M. J., G. S. Forbes, J. R. Grant, R. B. E. Lilly, and A. J. Waters, 1995: Images in Weather Forecasting: A Practical Guide for Interpreting Satellite and Rader Imagery. Cambridge University Press, 499 pp.

Chang, C.-P., S. C. Hou, H. C. Kuo, and G. T. J. Chen, 1998: The development of an intense East Asian summer monsoon disturbance with strong vertical coupling. Mon. Wea. Rev., 126, 2692-2712.

Chen, F., and J. Dudhia, 2001: Coupling an advanced land surface-hydrology model with the Penn State-NCAR MM5 modeling system. Part I: Model implementation and sensitivity. Mon. Wea. Rev., 129, 569-585.

Cho, H.-R., and G. T. J. Chen, 1995: Mei-yu frontogenesis. J. Atmos. Sci., 52, 2109-2120.

Eady, E. R., 1949: Long waves and cyclone waves. Tellus, 1, 33-52.

Grell, G. A., and D. Dévényi, 2002: A generalized approach to parameterizing convection combining ensemble and data assimilation techniques. Geophys. Res. Lett., 29, 38-1-38-4, doi:10.1029/2002GL015311.

Hong, S.-Y., and J.-O. J. Lim, 2006: The WRF single-moment 6-class Microphysics scheme (WSM6). J. Korean Meteor. Soc., 42, 129-151.

Kain, J. S., 2004: The Kain-Fritch convective parameterization: An update. J. Appl. Meteor., 43, 170-181.

Matsumoto, S., K. Ninomiya, and S. Yoshizumi, 1971: Characteristic features of "Baiu" front associated with heavy rainfall. J. Meteor. Soc. Japan, 49, 267-281. 
Montgomery, M. T., and B. F. Farrell, 1991: Moist surface frontogenesis associated with interior potential vorticity anomalies in a semigeostrophic model. J. Atmos. Sci., 48, 343-367.

Montgomery, M. T., and B. F. Farrell, 1992: Polar low dynamics. J. Atmos. Sci., 49, 2484-2505.

Moore, R. W., and M. T. Montgomery, 2004: Reexamining the dynamics of short-scale, diabatic Rossby waves and their role in midlatitude moist cyclogenesis. $J$. Atmos. Sci., 61, 754-768.

Moore, R. W., and M. T. Montgomery, 2005: Analysis of an idealized, three-dimensional diabatic Rossby vortex: A coherent structure of the moist baroclinic atmosphere. J. Atmos. Sci., 62, 2703-2725.

Moore, R. W., and M. T. Montgomery, 2013: Genesis criteria for diabatic Rossby vortices: A model study. Mon. Wea. Rev., 141, 252-263.

Moore, R. W., M. T. Montgomery, and H. C. Davies, 2008: The integral role of a diabatic Rossby vortex in a heavy snowfall event. Mon. Wea. Rev., 136, 18781897.

Ninomiya, K., and K. Kurihara, 1987: Forecast experiment of a long-lived meso- $\alpha$-scale convective system in Baiu frontal zone. J. Meteor. Soc. Japan, 65, 885-899.

Ninomiya, K., and T. Akiyama, 1992: Multi-scale features of Baiu, the summer monsoon over Japan and the East Asia. J. Meteor. Soc. Japan, 70, 467-495.

Ninomiya, K., and Y. Shibagaki, 2003: Cloud system families in the Meiyu-Baiu front observed during 1-10 July 1991. J. Meteor. Soc. Japan, 81, 193-209.

Noh, Y., W. G. Cheon, S. Y. Hong, and S. Raasch, 2003: Improvement of the K-profile model for the planetary boundary layer based on large eddy simulation data. Bound.-Layer Meteor, 107, 421-427.

Onogi, K., J. Tsutsui, H. Koide, M. Sakamoto, S. Kobayashi, H. Hatsushika, T. Matsumoto, N. Yamazaki, H. Kamahori, K. Takahashi, S. Kadokura, K. Wada, K. Kato, R. Oyama, T. Ose, N. Mannoji, and R. Taira, 2007: The JRA-25 Reanalysis. J. Meteor. Soc. Japan, 85, 369-432.

Parker, D. J., and A. J. Thorpe, 1995: Conditional convective heating in a baroclinic atmosphere: A model of convective frontogenesis. J. Atmos. Sci., 52, 1699-1711.

Plougonven, R., and C. Snyder, 2007: Inertia-gravity waves spontaneously generated by jets and fronts. Part I: Different baroclinic life cycles. J. Atmos. Sci., 64, 2502-2520.

Raymond, D. J., and H. Jiang, 1990: A theory for long-lived mesoscale convective systems. J. Atmos. Sci., 47, 3067-3077.
Schultz, D. M., and F. Zhang, 2007: Baroclinic development within zonally-varying flows. Quart. J. Roy. Meteor. Soc., 133, 1101-1112.

Shibagaki, Y., and K. Ninomiya, 2005: Multi-scale interaction process associated with development of a sub-synoptic-scale depression on the Meiyu-Baiu frontal zone. J. Meteor. Soc. Japan, 83, 219-236.

Skamarock, W. C., J. B. Klemp, J. Dudhia, D. O. Gill, D. M. Barker, M. G. Duda, X.-Y. Huang, W. Wang, and J. G. Powers, 2008: A description of the Advanced Research WRF version 3. NCAR Tech. Note TN4681STR, $113 \mathrm{pp}$.

Snyder, C., and R. S. Lindzen, 1991: Quasi-geostrophic wave-CISK in an unbounded baroclinic shear. $J$. Atmos. Sci., 48, 76-86.

Tagami, H., H. Niino, and T. Kato, 2007: A study of meso$\alpha$-scale disturbances on the Baiu front and their environmental field. J. Meteor. Soc. Japan, 85, 767-784.

Takayabu, I., 1991: “Coupling development": An efficient mechanism for the development of extratropical cyclones. J. Meteor. Soc. Japan, 69, 609-628.

Tochimoto, E., and T. Kawano, 2012: Development processes of Baiu frontal depressions. SOLA, 8, 9-12.

Tochimoto, E., and T. Kawano, 2017: Numerical investigation of development processes of Baiu frontal depressions. Part I: Case studies. J. Meteor. Soc. Japan, 95, 91-109.

Tochimoto, E., and H. Niino, 2017: Structural and environmental characteristics of extratropical cyclones associated with tornado outbreaks in the warm sector: an idealized numerical study. Mon. Wea. Rev., 145, 117-136.

Whitaker, J. S., and C. A. Davis, 1994: Cyclogenesis in a saturated environment. J. Atmos. Sci., 51, 889-908.

Yanase, W., and H. Niino, 2005: Effects of baroclinicity on the cloud pattern and structure of polar lows: A high-resolution numerical experiment. Geophys. Res. Lett., 32, L02806, doi:10.1029/2004GL020469.

Yanase, W., and H. Niino, 2007: Dependence of polar low development on baroclinicity and physical processes: An idealized high resolution numerical experiment. $J$. Atmos. Sci., 64, 3044-3067.

Yanase, W., and H. Niino, 2015: Idealized numerical experiments on cyclone development in the tropical, subtropical, and extratropical environments. J. Atmos. Sci., 72, 3699-3714. 